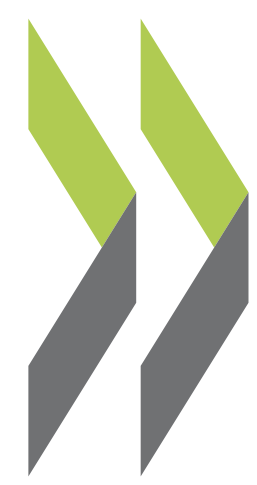

OECD Economics Department Working Papers No. 1521

Fan charts around GDP projections based on probit models of downturn risk

\section{David Turner,}

Thomas Chalaux, Hermes Morgavi 


\section{FAN CHARTS AROUND GDP PROJECTIONS BASED ON PROBIT MODELS OF DOWNTURN RISK}

\section{ECONOMICS DEPARTMENT WORKING PAPERS No. 1521}

\section{By David Turner, Thomas Chalaux and Hermes Morgavi}

OECD Working Papers should not be reported as representing the official views of the OECD or of its member countries. The opinions expressed and arguments employed are those of the authors.

Authorised for publication by Alain de Serres, Deputy Director, Policy Studies Branch, Economics Department.

All Economics Department Working Papers are available at www.oecd.org/eco/workingpapers.

JT03440987 
OECD Working Papers should not be reported as representing the official views of the OECD or of its member countries. The opinions expressed and arguments employed are those of the authors.

Working Papers describe preliminary results or research in progress by the authors and are published to stimulate discussion on a broad range of issues on which the OECD works.

Comments on Working Papers are welcomed, and may be sent to OECD Economics Department, 2 rue André Pascal, 75775 Paris Cedex 16, France, or by e-mail to eco.contact@oecd.org.

All Economics Department Working Papers are available at www.oecd.org/eco/workingpapers.

This document and any map included herein are without prejudice to the status of or sovereignty over any territory, to the delimitation of international frontiers and boundaries and to the name of any territory, city or area.

The statistical data for Israel are supplied by and under the responsibility of the relevant Israeli authorities. The use of such data by the OECD is without prejudice to the status of the Golan Heights, East Jerusalem and Israeli settlements in the West Bank under the terms of international law.

Latvia was not an OECD member at the time of preparation of this paper. Accordingly, Latvia is not included in the list of OECD countries and is not included in the area totals.

On 3 May 2018, the OECD Council invited Lithuania to become a Member. At the time of publication the deposit of Lithuania's instrument of accession to the OECD Convention was pending and therefore Lithuania does not appear in the list of OECD Members and is not included in the OECD zone aggregates.

On 25 May 2018, the OECD Council invited Colombia to become a Member. At the time of publication the deposit of Colombia's instrument of accession to the OECD Convention was pending and therefore Colombia does not appear in the list of OECD Members and is not included in the OECD zone aggregates.

\section{(c) OECD (2018)}

You can copy, download or print OECD content for your own use, and you can include excerpts from OECD publications, databases and multimedia products in your own documents, presentations, blogs, websites and teaching materials, provided that suitable acknowledgment of OECD as source and copyright owner is given. All requests for commercial use and translation rights should be submitted to rights@oecd.org 


\section{Abstract/Resumé}

\section{Fan charts around GDP projections based on probit models of downturn risk}

This paper describes a method for parameterising fan charts around GDP growth forecasts of the major OECD economies as well as the aggregate OECD. The degree of uncertainty - reflecting the overall spread of the fan chart - is based on past forecast errors, but the skew - reflecting whether risks are tilted to the downside - is derived from a probit model-based assessment of the probability of a future downturn.

This approach is applied to each of the G7 countries separately, with combinations of variables found to be useful in predicting future downturns at different horizons up to 8 quarters: at short horizons of 2-4 quarters, a flattening or inverted yield curve slope, recent sharp falls in house prices, share prices or credit; at longer horizons of 6-8 quarters, sustained strong growth in house prices, share prices and credit; and at all horizons, a tight labour market and rapid growth in OECD-wide (or in some cases euro-wide) house prices, share prices or credit. The in-sample fit of the probit models appears reasonably good for all G7 countries.

The predicted probabilities from the probit models provide a graduated assessment of downturn risk, which is reflected in the degree of skew in the fan chart. Fan charts computed on an out-of-sample basis around pre-crisis OECD forecasts published in June 2008 encompass the extreme outturns associated with the Global Financial Crisis for five of the G7 countries. A weakness of the approach is that, although it predicts a clear majority of past downturns, it will not predict atypical downturns. For example, in the current conjuncture, it is unlikely that current concerns about risks associated with Brexit, an escalation of trade tensions or spillovers from emerging markets would be picked up by the models. At the same time, a severe downturn triggered by such atypical events might be more severe if more typical risk factors are also high.

JEL Classification: E58, E17, E65, E66, E01.

Keywords: fan charts, economic forecasts, uncertainty, risk, downturn, recession.

$* * * * *$

Graphiques en éventail de prévisions du PIB basées sur des modèles probits de risque à la baisse

Ce papier décrit une méthode pour paramétrer des graphiques en éventail de prévisions du PIB des principales économies de l'OCDE et de l'OCDE en tant que tel. Le degré d'incertitude - reflétant la dispersion globale du graphique en éventail - est basé sur les erreurs passées de prévisions, mais l'asymétrie - reflétant si les risques sont à la baisse - est calculée grâce à l'estimation de la probabilité d'une baisse future par un modèle probit.

Cette approche est appliquée à chaque pays du G7 séparément, avec des combinaisons de variables utiles à prédire les baisses futures : à l'horizon proche de 2-4 trimestres, une courbe de rendement s'aplatissant ou inversée, des chutes brutales des prix du logement, des actions ou du crédit ; à horizons plus lointains, une croissance soutenue des prix du logement, des actions ou du crédit; et a tous horizons jusqu'à 8 trimestres, un marché du travail tendu et une croissance rapide dans la zone OCDE (dans certain cas dans la zone euro) des prix du logement, des actions ou du crédit. L'ajustement de l'échantillon des modèles probits ressort raisonnablement bien pour tous les pays du G7.

Les probabilités obtenues grâce aux modèles probits fournissent une évaluation graduelle du risque à la baisse, reflétée par le degré d'asymétrie du graphique en éventail. Les graphiques en éventail des prévisions de l'OCDE publiées en Juin 2008, calculées hors-échantillon, inclus les résultats extrêmes associés à la Crise pour cinq des pays du G7. Une faiblesse de cette approche est que, malgré le fait qu'elle prédise une claire majorité des crises passées, elle ne prédira pas des crises atypiques. Par exemple, dans la conjoncture actuelle, il est peu probable que les risques associés au Brexit, l'escalade des tensions commerciales ou l'impact des marchés émergents soient capturés par les modèles. En même temps, une crise sévère déclenchée par de tels évènements atypiques pourrait être encore pire si les facteurs typiques de risque étaient également élevés.

Codes JEL: E58, E17, E65, E66, E01.

Mots clés : graphiques en éventail, prévisions économiques, incertitude, risque, crise, récession. 


\section{Table of contents}

\section{FAN CHARTS AROUND GDP PROJECTIONS BASED ON PROBIT MODELS OF

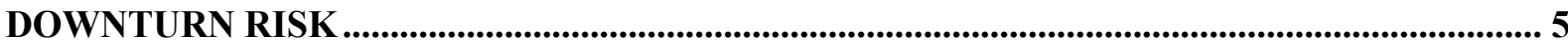

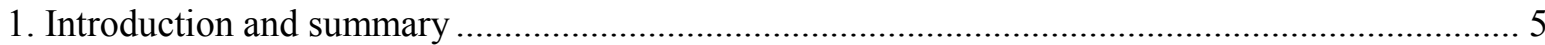

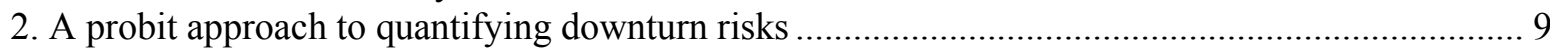

3. Linking quarterly probit probabilities to annual downturn risks ............................................. 14

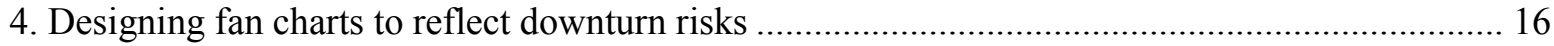

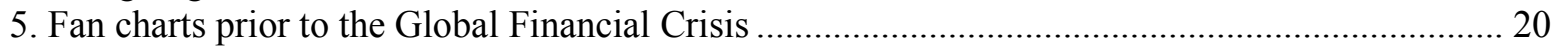

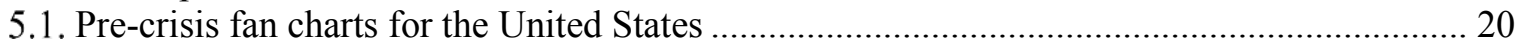

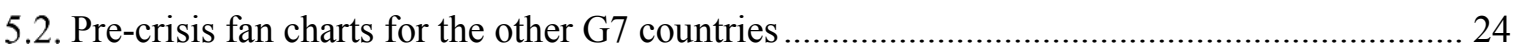

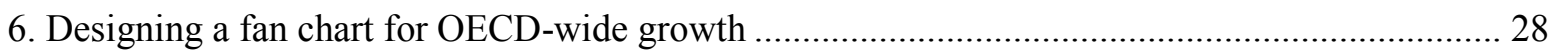

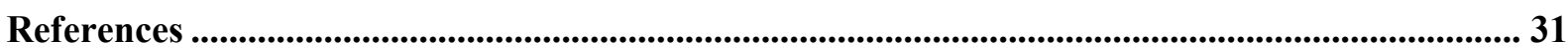

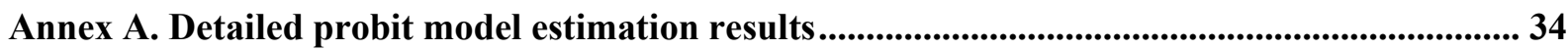

Annex B. The two-piece normal distribution and prediction intervals ............................................. 42

\section{Tables}

Table 1. Definition of severe downturn episodes for G7 countries ...................................................... 9

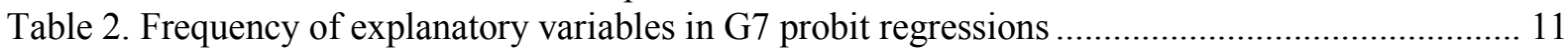

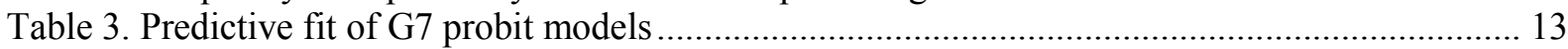

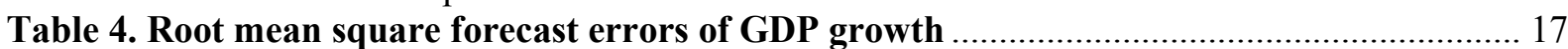

Table 5. Regressions of G7 forecast errors on downturn probabilities ............................................... 19

Table 6. The position of Global Financial Crisis G7 GDP outturns in pre-crisis fan charts ................ 27

Table 7. Probit regressions of a severe slowdown in OECD-wide growth ..........................................29

Table 8. Regressions of OECD GDP growth forecast errors on slowdown probabilities ..................... 29

\section{Figures}

Figure 1. OECD's track record in predicting recessions .................................................................... 7

Figure 2. Pooled normalised GDP growth forecast errors for all OECD countries............................... 8

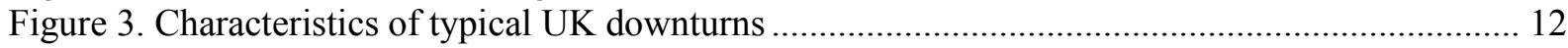

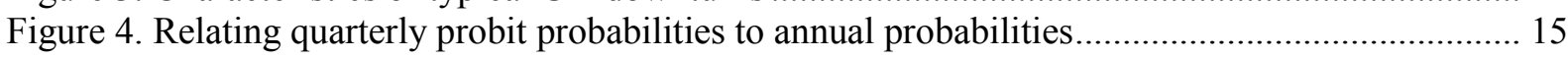

Figure 5. Fan charts for the June 2008 OECD forecast of the United States ....................................... 22

Figure 6. Fan charts for the December 2007 OECD forecast of the United States .............................. 23

Figure 7. Probit-based fan charts for June 2008 OECD forecasts for other G7 countries..................... 25

Figure 8. Probit-based fan charts for December 2007 OECD forecasts for other G7 countries ........... 26 


\title{
FAN CHARTS AROUND GDP PROJECTIONS BASED ON PROBIT MODELS OF DOWNTURN RISK
}

\author{
David Turner, Thomas Chalaux and Hermes Morgavi ${ }^{1}$
}

\section{Introduction and summary}

1. Macroeconomic forecasters have an abysmal track record in predicting future recessions as borne out by numerous surveys of different forecasters over various periods for many countries (for example: Loungani, 2001; Abreu, 2011; Fildes and Steckler, 2002; Pain and Lewis, 2014). OECD forecasts published in the OECD Economic Outlook are typical; since 1991, less than 10\% of forecasts for OECD countries published in May/June correctly identified a recession in the following year (Figure 1 ). ${ }^{2}$ OECD forecasts are also typical in being biased towards over-prediction, at least for forecasts beyond the current year, with the largest outliers corresponding to downturn periods, so that the distribution of forecast errors cannot be characterised by a normal distribution for forecast horizons beyond the current year (Figure 2). This skewness also makes it more difficult to assess and convey uncertainty surrounding GDP growth forecasts.

2. Previous OECD work has proposed a method to address these issues by constructing fan charts, which are parameterised based on the historical forecasting track record, but distinguish between a "safe" regime and a "downturn-risk" regime (Turner, 2017). To identify the two regimes, use was made of OECD work on early warning indicators of a prospective downturn (Hermansen and Röhn, 2016). Thus, when an early warning indicator is "flashing", the associated fan chart is not only wider to reflect increased uncertainty, but it is also skewed to reflect greater downside risks using a two-piece normal distribution of the form used by some central banks to provide fan charts around inflation forecasts. Conversely, in a safe regime, when the early warning indicators are not flashing, as well as being symmetric, the fan chart is narrower both relative to the downturn-risk regime and relative to what it would be if the dispersion were calculated with respect to the entire forecast track record with no distinction between regimes.

3. The current paper develops this methodology by using the probability of a future downturn from a probit model, in place of the binary ("alarm" or "no alarm") signal indicators, to parameterise the fan chart. The advantage of the new approach is that it allows

\footnotetext{
${ }^{1}$ The authors are all members of the Macroeconomic Analysis Division at the OECD Economics Department. Particular thanks are due to Jeroen Meyer for constructing a consistent historical database of forecast errors, without which this work would not have been possible. Thanks to Barbara Jarmulska (ECB) for the original inspiration to combine probit models with fan charts. Thanks for constructive comments from Nikki Kergozou (Paris School of Economics), Douglas Sutherland, Mauro Pisu, Andrew Barker, Luiz de Mello as well as many participants at the OECD's Working Party No.1, where a previous draft was discussed, as well as to Veronica Humi for editorial support.

${ }^{2}$ Figure 1 is based on a similar chart analysing IMF forecasts in a recent Financial Times article entitled "IMF shows poor track record in forecasting recessions" (Romei and Fray, 2018), which found that "Over the last 27 years, the IMF has predicted every October that an average of five economies will contract the following year. In practice, an average of 26 have contracted".
} 
a gradual transition in the skewness of the fan chart, rather than 'jumping' from symmetry to extreme skewness. It also facilitates having a greater number of variables to assess the downturn risk. ${ }^{3}$

4. The main findings of the paper are as follows:

- The probit equations for the G7 countries suggest that combinations of variables, which depend on the prediction horizon, are useful in explaining downturn risks: at short horizons of 2-4 quarters, a flattening or inverted yield curve slope, recent sharp falls in house prices, share prices or credit; at longer horizons, sustained strong growth in house prices, share prices and credit; and at all horizons up to 8 quarters, a tight labour market and rapid growth in OECD-wide (or in some cases euro-area-wide) house prices, share prices or credit. Downturn probabilities tend to spike when many of these variables are moving in the risk direction simultaneously.

- Following the probit approach, fan charts computed on an out-of-sample basis around the June 2008 forecasts encompass the extreme outcomes associated with the Global Financial Crisis within a 90\% prediction interval for five of the G7 countries. For the December 2007 forecasts, the probit-based fan charts appear less successful, encompassing the 2009 outturn for only three of the G7 countries, although all fan charts exhibit substantial downward skew, which might have conveyed a strong policy message given the simultaneous nature of these risks.

- A weakness of the probit-based approach is that, although it predicts an overwhelming majority of severe downturns in the G7, it will not predict atypical downturns, such as the UK downturn associated with the experiment with monetarism in the early 1980s or the downturn associated with the Asian crisis in Japan in 1997/98. In the context of the current macroeconomic conjuncture, this suggests that it would be unlikely to predict a downturn associated with a hardBrexit, spillovers from emerging markets or a global trade war. A challenge for future work will be to try to better incorporate such risks, particularly those that are transmitted as trade shocks.

- Future work could also consider extending the approach to other OECD countries. ${ }^{4}$

5. The remainder of the paper is organised as follows. The next section describes the approach to estimating a probit model for predicting a future downturn, which is then applied to each of the G7 economies. Section 3 explains how the quarterly probit probabilities of a downturn are converted into a form that can be related to annual forecast errors. Section 4 describes how the predicted downturn probabilities are used to parameterise fan charts around forecasts of GDP growth. In Section 5 the out-of-sample performance of this approach is evaluated by applying it to forecasts made just prior to the Global Financial Crisis. In Section 6, a method for computing a fan chart around OECD aggregate growth following the probit approach is described.

\footnotetext{
${ }^{3}$ A more detailed comparison of the two approaches (not presented here) also finds that the probit models have a clearly superior performance in predicting downturns (and non-downturns) compared to the binary early warning indicators, which is unsurprising given that the probit models use more explanatory variables and distinguish downturn risks at different horizons.

${ }^{4}$ Models for designing fan charts based on the same methodology have already been estimated for New Zealand (Kergozou and Turner, 2018) and for Sweden (Turner and Chalaux, forthcoming).
} 


\section{Figure 1. OECD's track record in predicting recessions}

\begin{tabular}{|c|c|c|}
\hline $\begin{array}{r}\text { OECD } \\
\text { Forecast }\end{array}$ & & Actual \\
\hline & 1991 & ||||| ||| \\
\hline | = incorrect & 1992 & $\||\|| \mid$ \\
\hline$=$ correct & 1993 & |||||||||| $\mid$ \\
\hline & 1994 & | \\
\hline & 1995 & \\
\hline & 1996 & | \\
\hline & 1997 & \\
\hline & 1998 & ||l| \\
\hline & 1999 & $\|$ \\
\hline | & 2000 & \\
\hline & 2001 & |l| \\
\hline & 2002 & | \\
\hline & 2003 & |l|| \\
\hline & 2004 & \\
\hline & 2005 & \\
\hline & 2006 & \\
\hline & 2007 & \\
\hline & 2008 & |||||||||| \\
\hline | & 2009 & |||||||||||||||||||||||||||||||||||| \\
\hline ||||| ||||| || & 2010 & |l|| \\
\hline | & 2011 & |l|| \\
\hline | & 2012 & |||||| |||||| | \\
\hline ||||| & 2013 & |||||||||| \\
\hline I & 2014 & III \\
\hline & 2015 & I \\
\hline & 2016 & | \\
\hline
\end{tabular}

Note: The chart summarises the incidence of recessions among all OECD countries, defined for the purpose of this chart as a negative GDP growth rate. Each black bar in the right-hand-side panel indicates a country experiencing a recession in that year. Each bar in the left-hand-side panel corresponds to the forecast that a country will experience a recession based on the Spring (May/June) edition of the OECD Economic Outlook in the preceding year, with a blue bar indicating that the country did actually experience a recession and a red bar indicating that it did not.

Source: OECD Economic Outlook databases. 


\section{Figure 2. Pooled normalised GDP growth forecast errors for all OECD countries}

(A) Spring current-year forecast errors, 2000-2016 Shapiro-Wilk test $=0.10(28.8 \%)$

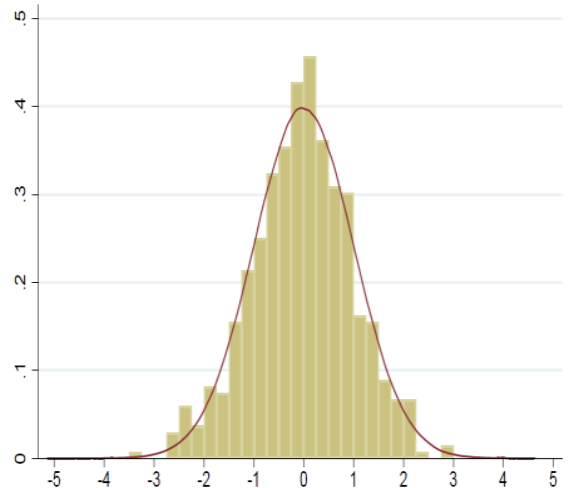

(C) Spring year-ahead forecast errors, 1981-2015 Shapiro-Wilk test $=4.46(<0.01 \%)$

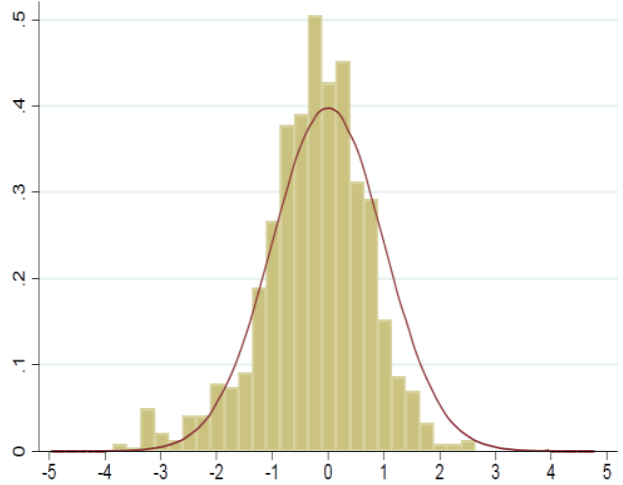

(B) Autumn year-ahead forecast errors, 1981-2015 Shapiro-Wilk test $=5.53(<0.01 \%)$

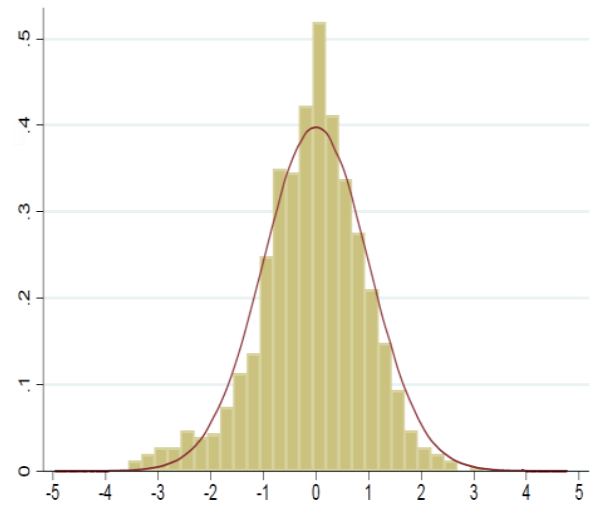

(D) Autumn 2-year-ahead forecast errors, 1990-2014 Shapiro-Wilk test $=6.11(<0.01 \%)$

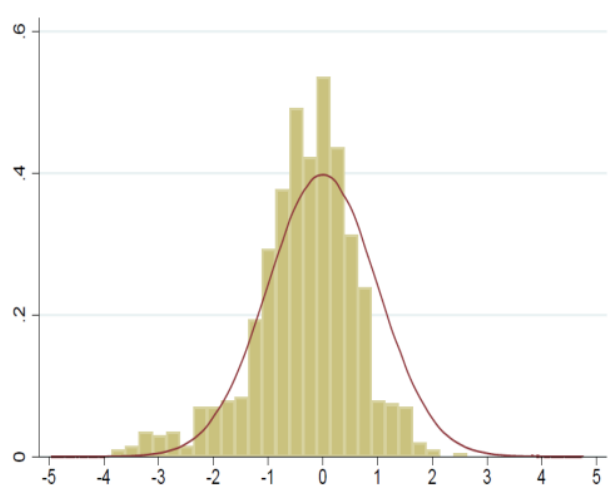

Note: These charts are designed to show whether OECD forecast errors of GDP growth for all OECD countries are normally distributed and unbiased at different forecast horizons. The null hypothesis is that forecast errors for each country are normally distributed with zero mean but with a country-specific variance that depends on the forecast horizon. Forecast errors are therefore normalised on each country's RMSE before being pooled for each forecast horizon. The red curve shows the hypothetical frequency distribution of a standard normal variable, to which the histograms should converge under the null hypothesis. Formal tests confirm the visual impression of the charts, namely that the null hypothesis is rejected at conventional levels of significance at forecast horizons beyond the current year. Shapiro-Wilk test statistics for normality are shown next to each chart with the p-value for not rejecting the null of normality in brackets. The sample period for the Spring current-year forecast errors is shortened because at this horizon there is evidence of a trend decline in the RMSE, with errors systematically lower after 2000. Autumn 2-year ahead forecasts were not published before 1990.

Source: OECD Economic Outlook databases. 


\section{A probit approach to quantifying downturn risks}

6. To identify downturn risks the approach here follows a well-developed literature in using probit models to assess the probability of a future downturn [see for example: Estrella and Mishkin (1997); Estrella (2007); Estrella et al. (2003); Dovern and Zieglar (2008); Fornari and Lemke (2010)]. For this purpose, a severe downturn episode is defined as a series of quarters in which: (i) GDP per capita falls in both the initial and final quarter of the episode; and (ii) the cumulative fall in GDP per capita is at least 2 percentage points over the entire episode (Table 1).

Table 1. Definition of severe downturn episodes for $\mathbf{G 7}$ countries

\begin{tabular}{|c|c|c|c|c|}
\hline & 1970s & $1980 \mathrm{~s}$ & 1990 s & $2000 \mathrm{~s}$ \\
\hline United States & 1973Q3-75Q1 & 1979Q4-80Q3; 1981Q2-82Q4 & 1990Q3-91Q1 & 2008Q1-09Q2 \\
\hline Japan & 1970Q2-71Q4; 1973Q2-75Q1 & & 1991Q3-94Q2; 1997Q2-99Q1 & 2008Q2-09Q1 \\
\hline Germany & 1974Q2-75Q2 & 1980Q2-82Q4 & 1992Q2-93Q4 & 2008Q2-09Q1 \\
\hline United Kingdom & 1973Q3-76Q2 & 1979Q3-81Q1 & 1990Q3-92Q2 & 2008Q2-09Q3 \\
\hline France & 1974Q4-75Q3 & & 1992Q2-93Q1 & 2008Q2-09Q2 \\
\hline Italy & 1974Q4-75Q2; 1977Q1-77Q3 & & 1992Q2-93Q3 & 2008Q2-09Q2; 2011Q2-14Q2 \\
\hline Canada & 1974Q3-75Q1 & 1981Q3-82Q4 & 1989Q2-92Q2 & 2008Q4-09Q2 \\
\hline
\end{tabular}

Note: Severe downturns are defined as episodes during which GDP per capita falls cumulatively by at least 2 percentage points. An exception is Japan, where the definition is analogous, but allows for high trend growth during the 1970s and 1980s (see text for details). Two episodes, highlighted in bold - 1997Q2-99Q1 for Japan and 1979Q3-81Q1 for the United Kingdom - are identified as severe downturns, but subsequently excluded from the regression analysis (see text for explanation).

7. A different definition of a severe downturn is applied to Japan because during the 1970s and 1980s it experienced much higher trend growth, so that even a substantial and prolonged decline in growth was insufficient to qualify as a severe downturn. For example, in the last five years of the 1980s, GDP per capita averaged 5\% per annum, while over the following five years, it averaged only $1 \frac{11 / 4}{4}$ per cent per annum, but none of the latter period qualifies as a severe downturn because GDP per capita growth was never sufficiently negative. Instead, an alternative but analogous downturn definition to that used for the other G7 countries is used, which adjusts for the higher trend growth of Japan during the 1970s and 1980s. ${ }^{5}$

8. Separate probit models are estimated to assess the risk of a future downturn at horizons of 2, 4, 6 and 8 quarters ahead. The dependent variable in the probit regression is then defined such that if that quarter is part of a severe downturn episode it takes the value unity and otherwise zero. Broadly speaking, two types of variables are tested for significance in the probit models, namely macro variables related to the business cycle and variables capturing developments in financial markets. The business cycle variables that

\footnotetext{
${ }^{5}$ For Japan the definition of a severe downturn takes trend growth, as measured by potential GDP per capita, as a reference point. To qualify as a severe downturn: (i) growth in GDP per capita must be lower than trend growth in both the initial and final quarter by at least $0.5 \%$; (ii) the cumulative fall in the growth of GDP per capita, relative to trend growth, is at least 2 percentage points plus 0.4 percentage points per quarter for which the downturn lasts. Here the 2 percentage points corresponds to the definition of the downturn used for other G7 countries and the $0.4 \%$ per quarter is equal to the average annual GDP per capita growth across the other G7 countries since 1970 in order to try to provide some comparability.
} 
are candidates for inclusion include: the slope of the yield curve, unemployment, inflation as well as other macro variables, including survey measures, which are commonly used in mixed frequency short-term bridge forecasting models of GDP (see for example, Ollivaud et al., 2016). The financial market variables which are included are those which previous OECD work (Hermansen and Röhn, 2016) has found to be the most reliable in predicting future severe downturns at horizons of up to eight quarters; these include credit growth, house prices and equity prices as well as OECD-wide (or occasionally euro area wide) developments in these same variables.

9. In the final preferred equations, the explanatory variables which are most commonly used across all G7 countries can be summarised as follows (summary in Table 2, full results in Annex A, Table A1):

- A relatively flat or negatively sloped yield curve increases downturn risk in most countries, but mostly at shorter ( 2 and 4 quarter) horizons.

- A positive unemployment gap, implying a tight or over-heating labour market, signals an increased downturn risk at all (2, 4, 6 and 8 quarter) horizons for most countries. ${ }^{6}$

- Recent weakness or negative growth in real house prices, credit and especially real share prices tends to signal an increased downturn risk, but only at short horizons (mostly 2 quarters).

- In contrast, sustained strong positive growth (over the previous three or five years) in real house prices, credit or real share prices increases downturn risk, particularly at longer horizons of 6 and 8 quarters. For some countries, a high level of real house prices, judged relative to disposable incomes or rents, also increases downturn risks at all horizons.

- Rapid sustained positive growth (over the previous three years) in OECD-wide or euro-area-wide house prices, credit or share prices increases risk at all horizons. All country models, with the exception of that for the United States, include such variables for at least one horizon, and most include them in two or three horizons.

10. It is also worth noting that a number of variables do not work. In particular, many of the variables that enter short-term indicator models of GDP - such as business or consumer surveys - do not help to explain downturn risks. The likely explanation for this finding is that indicator models typically attempt to predict the current or next quarter's GDP, whereas the probit models are concerned with downturn risk at a minimum of 2 quarters ahead. The only exception is that the Tankan measure of capacity utilisation is used, rather than the unemployment gap, in identifying business cycle turning points for Japan. Thus, at shorter horizons a high level of capacity utilisation as well as a declining rate of capacity utilisation are both risk factors; the combination of these two functional forms should pick up the passing of a cyclical peak.

11. It perhaps less surprising that inflation is not a reliable predictor of downturns given the marked change in its volatility over the sample estimation period. The inclusion of a variable measuring the annual growth of conceptions was also tested in the US probit

${ }^{6}$ The unemployment gap is computed as the OECD's measure of equilibrium unemployment described in Rusticelli et al. (2015) less the actual unemployment rate. 
equations following the findings of Buckles et al. (2018), but did not improve any of the models.

Table 2. Frequency of explanatory variables in $G 7$ probit regressions

Sample period begins in the early or mid-1970s and runs to $2018 \mathrm{Q} 3$

\begin{tabular}{|c|c|c|c|c|}
\hline \multirow{2}{*}{$\begin{array}{l}\text { Binary dependent variable: } \\
1=\text { downturn, } 0=\text { otherwise. }\end{array}$} & \multicolumn{4}{|c|}{ Probit regression at horizon of $Q$ quarters } \\
\hline & $Q=2$ & $\mathrm{Q}=4$ & $\mathrm{Q}=6$ & $\mathrm{Q}=8$ \\
\hline Yield curve slope & $=-=$ & $-=-$ & $=-$ & - \\
\hline Unemployment gap ${ }^{1}$ & ++++ & +++ & +++++ & +++ \\
\hline \multicolumn{5}{|l|}{ Real share prices } \\
\hline 1-year growth rate & $-=-$ & & & \\
\hline 3-year growth rate & & & & ++ \\
\hline \multicolumn{5}{|l|}{ Real house prices } \\
\hline 1-year growth rate & $=-$ & $=$ & & \\
\hline 3- or 5-year growth rate & & + & ++ & ++ \\
\hline Level (price-to-rent or price-to-income) & ++ & ++ & ++ & ++ \\
\hline \multicolumn{5}{|l|}{ Domestic credit } \\
\hline 1-year growth rate & -- & -- & & \\
\hline 3- or 5-year growth rate & + & + & +++ & +++ \\
\hline \multicolumn{5}{|l|}{ OECD or euro area house prices } \\
\hline 1-year growth rate & -- & - & & \\
\hline 3-year growth rate & ++ & ++ & +++ & +++ \\
\hline \multicolumn{5}{|l|}{ OECD-wide credit } \\
\hline 2- or 3-year growth rate & +++ & +++ & + & ++ \\
\hline \multicolumn{5}{|l|}{ OECD or euro area share prices } \\
\hline 3-year growth rate & & & + & + \\
\hline
\end{tabular}

Note: The table summarises the frequency with which explanatory variables are used in each of the G7 probit regressions at different horizons with each "+" ("-") denoting a positive (negative) statistically significant coefficient for one country. Thus " ++++ " denotes that variable appears in four country equations at that horizon with a positive sign. For the purposes of this table, similar variables are grouped together; for example, bank credit and total private credit are both classified as "domestic credit" and the houseprice-to-income ratio and house-price-to-rent ratio are both classified as "real house price" variables. In addition, there are a few country-specific explanatory variables not shown in the table, in particular: in the 2 and 4 quarter models for Italy, the long-term interest rate differential with Germany is included for the period since the creation of the euro; the growth rate of US house prices is included in the 8 quarter model for Canada; and a survey measure of manufacturing capacity utilisation appears in the 2 and 4 quarter models for Japan. Full details of all equations are given in Annex A.

For the probit regression at a horizon of $\mathrm{Q}$ quarters $(\mathrm{Q}=2,4,6$, or 8$)$ all explanatory variables enter the equations lagged by $\mathrm{Q}$ quarters except house price variables which are lagged an extra quarter and credit variables which are lagged an extra 2 quarters (because of the longer lags in data availability).

1. The unemployment gap is the OECD measure of equilibrium unemployment less the unemployment rate, so that a positive value indicates that the labour market is overheating. 
12. After some experimentation, two downturn episodes were excluded from the final preferred equations because they were judged to be 'atypical' downturns and excluding them improved the fit of the probit models. The two episodes which were excluded are the downturn of 1979/81 in the United Kingdom associated with the Thatcher government's experiment with monetarism and the downturn of 1997/8 in Japan associated with the Asia crisis: $^{7}$

- The downturn in the United Kingdom in the early 1980s was driven by policy decisions to target the money supply in order to reduce inflation, which led to high interest rates and a marked appreciation of sterling (Buiter and Miller, 1981). In contrast, all other severe downturns in the United Kingdom were preceded by a sustained build-up in real house prices and rapid OECD-wide credit growth (Figure 3).

- The downturn in Japan in 1997/98 was driven by the Asian financial crisis, possibly exacerbated by a large increase in indirect taxes, but neither of these factors is captured by the explanatory variables included in the probit models. The downturn associated with the Asian financial crisis was also excluded from a similar probit model estimated for New Zealand for similar reasons (Kergozou and Turner, 2018).

Figure 3. Characteristics of typical UK downturns

(A) OECD-wide credit-to-GDP

Average annual percentage point change over previous 3 years

4

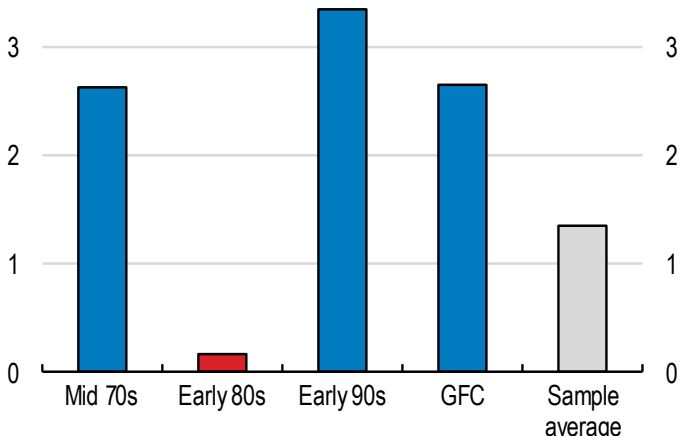

(B) UK house-price-to-rent ratio Average annual $\%$ change over previous 5 years

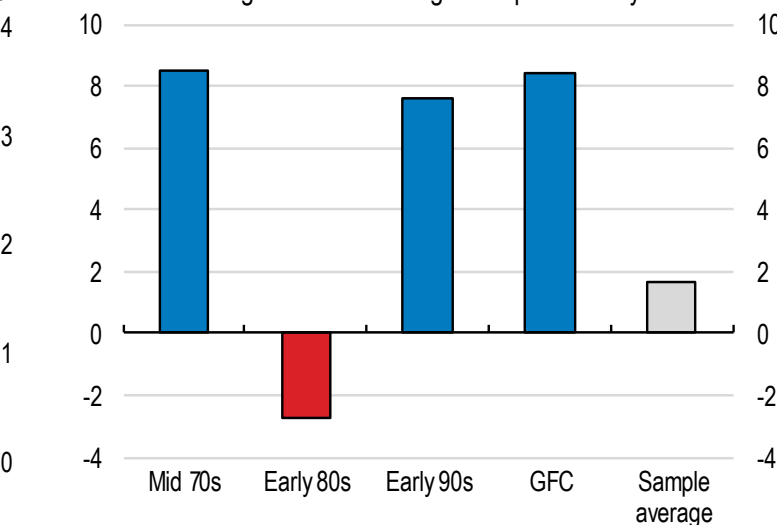

Note: Figures show the explanatory variables in the functional form used in the 8-quarter probit model for the United Kingdom, 8 quarters ahead of each downturn, where 'Sample average' denotes the average over the full sample estimation period.

13. The in-sample fit of the probit models appears reasonably good (Table 3). Taking a probit probability threshold of $15 \%$, above which the model is classified as predicting a

\footnotetext{
${ }^{7}$ For the United Kingdom, including the early 1980s downturn, reduces the predictive fit of the probit model at an 8 -quarter horizon from $94 \%$ to $84 \%$, with the coefficients on some explanatory variables becoming insignificant, but there is much less effect at shorter horizons. For Japan, including the Asian crisis downturn reduces the predictive fit of the probit model at all horizons by between $12 \%$ and $17 \%$, with several explanatory variables becoming insignificant.
} 
downturn, the models typically correctly predict around $90 \%$ of all downturn and non-downturn episodes. Even with this apparently high level of predictive fit, the implication is that nearly $40 \%$ of downturn predictions are "false alarms' ${ }^{8}$ However, further scrutiny suggests that the majority of these false alarms are either close to a severe downturn episode (See Annex A, Figure A.1) or else predicted a period of negative GDP per capita growth that was not severe enough to be classified as part of downturn episode. ${ }^{9}$ It is also apparent that, after excluding the two "atypical" downturns described above, the models predict the overwhelming majority of G7 downturns (Annex A, Figure A1).

Table 3. Predictive fit of G7 probit models

\begin{tabular}{|c|c|c|c|c|c|c|}
\hline \multicolumn{7}{|c|}{$\%$ of correct predictions } \\
\hline & & \multicolumn{4}{|c|}{ Probit regression at horizon of $Q$ quarters } & \multirow{2}{*}{ Average } \\
\hline & & $Q=2$ & $Q=4$ & $Q=6$ & $Q=8$ & \\
\hline \multirow{2}{*}{ United States } & Downturns & 92 & 81 & 89 & 81 & 86 \\
\hline & Non--downturns & 89 & 88 & 83 & 78 & 85 \\
\hline \multirow{2}{*}{ Japan } & Downturns & 88 & 94 & 88 & 94 & 91 \\
\hline & Non--downturns & 90 & 90 & 91 & 93 & 91 \\
\hline \multirow{2}{*}{ Germany } & Downturns & 93 & 93 & 92 & 96 & 94 \\
\hline & Non--downturns & 86 & 91 & 91 & 91 & 90 \\
\hline \multirow{2}{*}{ United Kingdom } & Downturns & 92 & 95 & 90 & 94 & 93 \\
\hline & Non--downturns & 91 & 93 & 90 & 90 & 91 \\
\hline \multirow{2}{*}{ France } & Downturns & 92 & 92 & 92 & 82 & 90 \\
\hline & Non--downturns & 93 & 92 & 90 & 92 & 92 \\
\hline \multirow{2}{*}{ Italy } & Downturns & 87 & 87 & 80 & 96 & 88 \\
\hline & Non--downturns & 83 & 87 & 77 & 85 & 83 \\
\hline \multirow{2}{*}{ Canada } & Downturns & 92 & 88 & 95 & 100 & 94 \\
\hline & Non--downturns & 91 & 88 & 93 & 89 & 90 \\
\hline \multirow{2}{*}{ G7 average } & Downturns & 91 & 90 & 89 & 92 & 91 \\
\hline & Non--downturns & 89 & 90 & 88 & 88 & 89 \\
\hline
\end{tabular}

Note: The threshold for the probit probability, by which the prediction is classified as a downturn, is taken to be $15 \%$ for all countries, where $15 \%$ is roughly the share of all quarters during which a large sample of OECD countries experience a downturn.

\footnotetext{
${ }^{8}$ If $90 \%$ of all predictions are correct in identifying downturns and non-downturns, and downturns are $15 \%$ of all periods, then the proportion of all downturn predictions which are false alarms is calculated as: $(0.10 \times 0.85) /[(0.90 \times 0.15)+(0.10 \times 0.85)]=39 \%$ approximately. The intuition for such a high proportion is that a $10 \%$ failure in predicting a relatively large number of non-downturns (the false alarms) can still be relatively high in comparison to a $90 \%$ success rate in predicting much rarer downturns.

${ }^{9}$ The proportion of downturn predictions that are false alarms falls below $10 \%$ after excluding downturn predictions, which are either (i) within 4 quarters of the start or end of a severe downturn episode or (ii) result in negative GDP per capita growth, but not by enough to be classified as a downturn.
} 


\section{Linking quarterly probit probabilities to annual downturn risks}

14. While OECD forecasts published in the OECD Economic Outlook do have a quarterly profile, the forecasts themselves are more commonly discussed in annual form, partly reflecting the large number of countries that the forecasts cover. In order to represent the risk around the annual GDP growth forecasts, it is first necessary to convert the quarterly probit probabilities of a downturn risk into the corresponding risk for an annual forecast.

15. The calculation of an annual risk measure, and in particular, how it is related to the quarterly probit probabilities, depends on the forecast horizon (Figure 4). For example, consider a Spring forecast that is published towards the end of the second quarter in year $\mathrm{T}$, where it can be assumed that most data are available for the first quarter of year $\mathrm{T}$ at the time of publication (Figure 4, panel B). The risk of a downturn in the following year is then calculated as a weighted average of the probit probabilities of a future downturn two, four and six quarters in advance. From the perspective of the first quarter of year $\mathrm{T}$ (for which the most recent data will be available), this corresponds to a weighted average of a downturn in the third quarter of year $\mathrm{T}$ and the first and third quarters of year $(\mathrm{T}+1)$. The probabilities are given weights reflecting the importance of the quarterly growth rates in the calculation of annual growth of year $(T+1)$ relative to year $T$ (Cross and Wyman, 2011). Thus, in the case of the Spring year-ahead forecast, the probability of a downturn in the first quarter of year $(\mathrm{T}+1)$ is given double the weight of the probabilities of a downturn in the third quarter of years $\mathrm{T}$ and $(\mathrm{T}+1)$. Annual probabilities can be calculated for the Spring current-year, Autumn one-year-ahead and Autumn two-year-ahead forecasts in a similar fashion. 


\section{Figure 4. Relating quarterly probit probabilities to annual probabilities}

(A) Autumn year-ahead forecast:

Probability of a downturn, $\mathrm{P}^{\mathrm{A}, \mathrm{T}+1}=(2 / 3)^{*} \mathrm{p}_{2}+(1 / 3)^{*} \mathrm{p}_{4}$

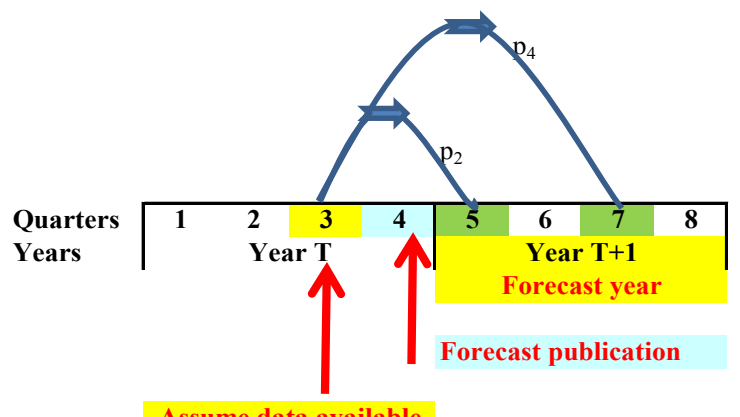

Assume data available

(B) Spring year-ahead forecast:

Probability of a downturn, $\mathrm{P}^{\mathrm{S}, \mathrm{T}+1}=0.25 * \mathrm{p}_{2}+0.5 * \mathrm{p}_{4}+0.25 * \mathrm{p}_{6}$

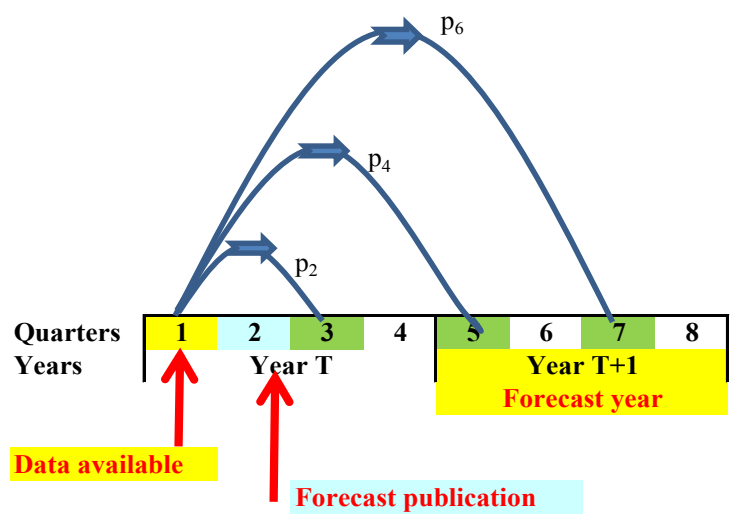

(C) Autumn two-year-ahead forecast:

Probability of a downturn, $\mathrm{P}^{\mathrm{A}, \mathrm{T}+2}=0.25 * \mathrm{p}_{4}+0.5 * \mathrm{p}_{6}+0.25 * \mathrm{p}_{8}$

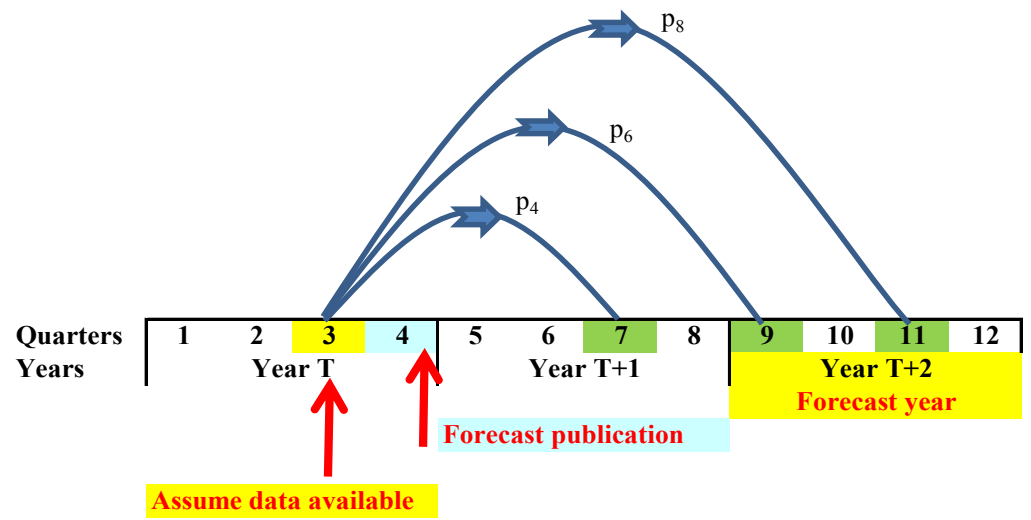

Note: The chart summarises how quarterly probit probabilities, $\mathrm{p}_{\mathrm{n}}$, of a future downturn at an horizon of $\mathrm{n}$ quarters $(n=2,4,6$, or 8$)$ are converted to an annual probability of a future downturn, $\mathrm{P}^{\mathrm{s}}$, $\mathrm{T}+\mathrm{i}$, where $\mathrm{s}$ represents whether the forecast is published in the Spring $(\mathrm{s}=\mathrm{S})$ or Autumn $(\mathrm{s}=\mathrm{A})$ of year $\mathrm{T}$ and the forecast is for year $(\mathrm{T}+\mathrm{i})$, where the forecast horizon is $\mathrm{i}=1$ or 2 years. A Spring (Autumn) forecast is published towards the end of the second (fourth) quarter, so that most data for the quarterly probit model will be available up to the first (third) quarter. 


\section{Designing fan charts to reflect downturn risks}

16. Fan charts are easily interpretable visual devices, which serve to emphasise the uncertainty surrounding a forecast. The Bank of England and Riksbank were the first to use fan charts in macroeconomic forecasting, although their use has since spread among many central banks as well as other major national and international institutions (see World Bank [2016] for a recent survey). For the Bank of England, the width of the fan chart is initially based on the dispersion of outturns around previous forecasts, but this is then modified by the Monetary Policy Committee based on their judgement as to whether uncertainty looking forward is likely to be greater or less than that past experience, and whether risks are skewed to the up- or down-side (Britton et al., 1997; Bank of England, 2005). The Riksbank has also published a regular Monetary Policy Report since 1997 containing its inflation forecasts for inflation and GDP with uncertainty bands around the forecast. When the fan charts were first introduced, the underlying distribution was informed by model simulations of shocks that were judged likely to influence the forecast (Blix and Sellin, 1998). However, since 2007, Riksbank fan charts are based on historical errors, with fan chart intervals calculated using the historical RMSE and assuming that errors are normally distributed, so implying symmetric fan charts (Sveriges Riksbank, 2007).

17. The approach to parameterising a fan chart advocated here is based on past forecast errors, but with the risk of a future severe downturn derived from the quarterly probit models also reflected in the dispersion of the fan chart as follows: ${ }^{10}$

- If the risk of a future downturn is very low, so that the annual probability of a downturn is below a threshold value (here, somewhat arbitrarily, taken to be 5\%), it is assumed that possible outcomes are normally distributed around the published forecast, which is assumed to be the modal outcome. Given the symmetry of the normal distribution, the modal outcome is also the mean outcome. The dispersion of possible outcomes is based on the historical RMSFE during periods in which the probit probability was below the threshold value, which is much smaller than the RMSFE over the entire forecast track record (Table 4).

- If the risk of a downturn according to the probit model is significant (above the threshold value), then possible outcomes are assumed to be skewed to the downside, with the extent of the skew related to the size of the downturn risk. In this case, forecast errors are assumed to follow a two-piece normal distribution, which is parameterised by using the historical relationship between downturn probabilities and past forecast errors, as described below.

\footnotetext{
${ }^{10}$ Two further details of how the fan charts are constructed are discussed in Annex B, namely: the use of highest probability density intervals rather than central prediction intervals; and the number of prediction intervals. Both are important in determining the appearance of the fan chart, but neither is central to the main argument about the importance of distinguishing downturn risks.
} 
Table 4. Root mean square forecast errors of GDP growth

\begin{tabular}{lcccccccc} 
& USA & JPN & DEU & FRA & GBR & ITA & CAN & OECD \\
\hline Autumn year-ahead & & & & & & & & \\
(1) Full sample & 1.11 & 1.53 & 1.30 & 0.94 & 1.16 & 1.26 & 1.61 & 0.94 \\
(2) 'Safe' periods & 1.06 & 1.26 & 0.98 & 0.75 & 0.76 & 1.07 & 1.17 & 0.63 \\
Ratio (2)/(1) & 0.95 & 0.82 & 0.75 & 0.80 & 0.66 & 0.85 & 0.73 & 0.67 \\
Spring year-ahead & & & & & & & & \\
(1) Full sample & 1.50 & 2.09 & 1.85 & 1.41 & 1.62 & 1.91 & 2.05 & 1.40 \\
(2) 'Safe' periods & 1.26 & 1.66 & 1.26 & 1.00 & 1.01 & 1.34 & 1.18 & 0.83 \\
Ratio (2)/(1) & 0.84 & 0.79 & 0.68 & 0.71 & 0.62 & 0.70 & 0.58 & 0.59 \\
Autumn two-year-ahead & & & & & & & & \\
(1) Full sample & 1.55 & 2.17 & 1.96 & 1.53 & 1.87 & 2.05 & 1.73 & 1.49 \\
(2) 'Safe' periods & 1.03 & 1.45 & 1.40 & 1.10 & 0.97 & 1.31 & 1.17 & 0.69 \\
Ratio (2)/(1) & 0.66 & 0.67 & 0.71 & 0.72 & 0.52 & 0.64 & 0.68 & 0.47 \\
\hline
\end{tabular}

Note: The full sample RMSFEs are calculated over the periods 1980-2017, 1982-2017 and $1989-2017$ for the Autumn year-ahead, Spring year-ahead and Autumn two-year ahead forecasts, respectively. 'Safe' periods are defined as years in which the annualised prediction of the downturn probabilities from the probit model is less than $5 \%$.

18. The two-piece normal distribution can be summarised in terms of three parameters - the mode $(\mu)$ and two standard deviations $\left(\sigma_{1}\right.$ and $\left.\sigma_{2}\right)$ - and is formed by taking two halves of normal distributions with parameters $\left(\mu, \sigma_{1}\right)$ and $\left(\mu, \sigma_{2}\right)$, and scaling them so that the probability density functions have a common value at the mode (see Annex B). With $\sigma_{1}>\sigma_{2}$ the distribution will have negative skewness, and the relationship between the mean outcome $\left(\mu^{*}\right)$ and mode is given by (see John, 1982):

$$
\mu-\mu^{*}=\mathrm{k}\left(\sigma_{1}-\sigma_{2}\right) \text {, where } \mathrm{k}=(2 / \pi)^{1 / 2}
$$

19. To estimate the three parameters of the two-piece normal distribution for the downturn-risk regime, the following assumptions are made:

- The published forecast is the modal outcome, $\mu$.

- The smaller standard deviation, $\sigma_{2}$, of the upper half of the distribution can be approximated by the RMSE of forecast errors in periods when there is deemed to be little risk of a downturn (i.e. when the probit probability of a downturn is less than $5 \%$ ). The reasoning is that if the outcome exceeds the published forecast so that there is no severe downturn, then there is little reason to expect the forecast error to be exceptional and hence it can be evaluated by the past forecast performance during safe periods.

- The larger standard deviation, $\sigma_{1}$, of the lower half of the distribution is computed by first quantifying the historical relationship between the mean forecast error and the probit probability of a downturn. Any observed non-trivial probability of a downturn can be converted into a predicted mean forecast error, which then, given the assumptions for $\mu$ and $\sigma_{2}$ above, can be used to determine $\sigma_{1}$ using equation [1].

20. The relationship between the mean forecast error and the probit probability of a downturn is estimated from a regression of historical annual forecast errors, $\epsilon_{t}^{s, t+i}$ distinguishing whether the associated forecasts were published in the Spring $(\mathrm{s}=\mathrm{S})$ or Autumn $(\mathrm{s}=\mathrm{A})$ of year $\mathrm{t}$ and for which year $(\mathrm{t}+\mathrm{i})$ the forecasts were made (where $\mathrm{i}=0,1$ or 2). Thus, separate regressions of the form of equation (2) are run for each of: the Spring current year forecast errors $\left(\epsilon_{t}^{S, t}\right)$; the Spring year-ahead forecast errors $\left(\epsilon_{t}^{S, t+1}\right)$; the Autumn year-ahead forecast errors; $\left(\epsilon_{t}^{A, t+1}\right)$; and the Autumn two-year-ahead forecast errors $\left(\epsilon_{t}^{A, t+2}\right)$. Thus, regressions take the following form: 


$$
\epsilon_{t}^{s, t+i}=\alpha^{s, t+i}+\beta^{s, t+i} P_{t}^{s, t+i}
$$

where $P_{t}^{s, t+i}$ is the corresponding annualised probability of a downturn derived from the quarterly probit model probabilities, which in turn, depend on the business cycle and financial market vulnerability indicators. In all cases, care is taken to ensure that data used to assess the future downturn probability would have been available at the time the forecast was published.

21. The approach described above is applied to each of the G7 economies in turn; forecast errors are regressed on the corresponding risks of a downturn in the period being forecast, with separate regressions distinguishing when the forecast was made (Spring or Autumn) and the forecast horizon (current year, year-ahead or two-year-ahead). The results can be summarised as follows (Table 5):

- With few exceptions, the estimated $\beta$ coefficients on the downturn probability are strongly statistically significant, large and negative for both Spring and Autumn forecasts and for all horizons beyond the current year, implying that increased risk of a downturn is strongly associated with forecast over-predictions. The only exception is Germany at the two-year ahead forecast horizon, where the $\beta_{1}$ coefficient is not statistically significant, although the coefficient is still large and negative so that a large downturn probability would still imply negative skew to the fan chart.

- The $\beta$ coefficients on the Spring current-year forecast are much smaller and less statistically significant than the same coefficients estimated at longer horizons. This is consistent with the finding in the introductory section that current-year forecasts appear unbiased with errors that are normally distributed. This is perhaps not entirely surprising, given that by the time of the Spring forecast publication (at the end of May or in early June), growth outturns for the first quarter will be known and hard monthly indicators will provide guidance on the second quarter outcome and these two quarters represent a substantial weight in the annual growth outcome for the current year.

- The intercept terms $(\alpha)$ are relatively small and statistically insignificant in most regressions, suggesting that when the probability of a future downturn is negligible, then forecasts are unbiased. 
Table 5. Regressions of G7 forecast errors on downturn probabilities

\begin{tabular}{|c|c|c|c|c|}
\hline \multirow{3}{*}{$\begin{array}{l}\text { Forecast published in } \\
\text { Forecast horizon }\end{array}$} & \multicolumn{4}{|c|}{ Dependent variable: forecast error, $\epsilon_{\mathrm{t}}{ }^{(\mathrm{s}, \mathrm{t}+\mathrm{i})}$} \\
\hline & Spring & Autumn & Spring & Autumn \\
\hline & curent-year & year-ahead & year-ahead & 2-years-ahead \\
\hline Sample period & $1981-2017$ & $1980-2017$ & $1982-2017$ & $1989-2017$ \\
\hline \multicolumn{5}{|l|}{ United States } \\
\hline Intercept term, ( $\alpha)$ & -0.01 & 0.25 & 0.10 & 0.18 \\
\hline Downturn probability $P,(\beta)$ & -0.10 & $-1.31^{*}$ & $-3.44^{* *}$ & $-4.69^{* * *}$ \\
\hline R-sqd adjusted & -0.04 & 0.05 & 0.14 & 0.21 \\
\hline \multicolumn{5}{|l|}{ Japan } \\
\hline Intercept term, ( $\alpha)$ & 0.16 & 0.09 & -0.01 & -0.20 \\
\hline Downturn probability $P,(\beta)$ & -0.16 & $-2.48^{\star *}$ & $-3.01^{*}$ & $-2.86^{*}$ \\
\hline R-sqd adjusted & 0.11 & 0.25 & 0.19 & 0.24 \\
\hline \multicolumn{5}{|l|}{ Germany } \\
\hline Intercept term, ( $\alpha)$ & 0.08 & 0.11 & -0.15 & -0.44 \\
\hline Downturn probability $P,(\beta)$ & 0.14 & $-1.53^{*}$ & $-3.21^{* * *}$ & -1.81 \\
\hline R-sqd adjusted & -0.03 & 0.07 & 0.16 & 0.02 \\
\hline \multicolumn{5}{|l|}{ United Kingdom } \\
\hline Intercept term, ( $\alpha)$ & 0.07 & $0.27^{*}$ & 0.17 & -0.18 \\
\hline Downturn probability $P,(\beta)$ & $-0.93^{\star *}$ & $-3.54^{\star \star *}$ & $-4.24^{* * *}$ & $-3.73^{\star \star *}$ \\
\hline R-sqd adjusted & 0.12 & 0.53 & 0.47 & 0.28 \\
\hline \multicolumn{5}{|l|}{ France } \\
\hline Intercept term, $(\alpha)$ & 0.04 & -0.02 & -0.29 & -0.31 \\
\hline Downturn probability $P,(\beta)$ & -0.35 & $-3.15^{\star \star *}$ & $-4.08^{* * *}$ & $-4.99^{* * *}$ \\
\hline R-sqd adjusted & -0.02 & 0.29 & 0.28 & 0.33 \\
\hline \multicolumn{5}{|l|}{ Italy } \\
\hline Intercept term, (a) & -0.18 & -0.20 & $-0.65^{\star \star}$ & $-0.74^{* *}$ \\
\hline Downturn probability $P,(\beta)$ & -0.23 & $-2.06^{\star * *}$ & $-2.79^{\star *}$ & $-2.97^{\star *}$ \\
\hline R-sqd adjusted & -0.04 & 0.15 & 0.14 & 0.17 \\
\hline \multicolumn{5}{|l|}{ Canada } \\
\hline Intercept term, ( $\alpha)$ & 0.01 & -0.01 & -0.17 & $-0.57^{\star}$ \\
\hline Downturn probability $P,(\beta)$ & $-1.35^{\star * *}$ & $-1.95^{*}$ & $-4.02^{* * *}$ & $-2.11^{* *}$ \\
\hline R-sqd adjusted & 0.20 & 0.08 & 0.32 & 0.14 \\
\hline
\end{tabular}

Note: The table reports the coefficient estimates from regressions $\epsilon_{t}^{s, t+i}=\alpha^{s, t+i}+\beta^{s, t+i} P_{t}^{s, t+i}$, explaining annual forecast errors, $\epsilon_{t}^{s, t+i}$, distinguishing whether the associated forecasts were published in the Spring $(\mathrm{s}=\mathrm{S})$ or Autumn $(\mathrm{s}=\mathrm{A})$ of year $\mathrm{t}$ and for which year $(\mathrm{t}+\mathrm{i})$ the forecasts were made (where $\mathrm{i}=0,1$ or 2). These errors are then explained in terms of the corresponding annualised probability of a slowdown, $P_{t}^{s, t+i}$, derived from the predicted quarterly probit model probabilities of the equations in Annex Table A. Statistical significance of coefficients at the $1 \%, 5 \%$ and $10 \%$ levels are denoted by '***', '**' and '*', respectively. 


\section{Fan charts prior to the Global Financial Crisis}

22. The probit-model approach is evaluated by using it to construct fan charts around OECD forecasts made just prior to the financial crisis, published in the first half of 2008 or at the end of 2007. These fan charts are compared with a benchmark 'straw man' approach in which the fan chart is constructed under the assumption that forecast errors are normally distributed (and so symmetrical) with the historical forecast RMSE being used to parameterise the distribution. ${ }^{11}$ The pre-crisis forecasts and associated fan charts are discussed in detail for one country, the United States, with the fan charts for the other G7 countries provided in a more summary form.

23. To parameterise the fan charts for historical forecasts, the probit models are run as strictly out-of-sample exercises, so that no data beyond 2008Q1 is used, directly or indirectly. ${ }^{12}$ This requires that all the quarterly probit regressions of downturn risk as well as the regression of forecast errors on annualised risks are rerun on the reduced sample. As the unemployment gap is computed with trend components, which are subject to historical revisions, the re-estimated equations use those series published at the time of the December 2007 and June 2008 Economic Outlooks. In most cases, reducing the sample period has surprisingly little effect on the goodness-of-fit of the probit regressions and the majority of explanatory variables remain statistically significant and correctly signed. Similarly, the slope coefficients $\left(\beta_{1}\right.$ 's) remain large and statistically significant in the regressions linking forecast errors and annualised downturn probabilities.

\subsection{Pre-crisis fan charts for the United States}

24. The June 2008 forecast for the United States was for a moderation of growth from $2 \frac{1}{4}$ in 2007 to just over $1 \%$ per annum in 2009 . The accompanying commentary recognised that risks were unusually elevated, but without any emphasis on the downside: "Risks have widened. There is considerable uncertainty about the eventual scale of financial losses....These risks could go either way."

25. A benchmark symmetric fan chart is computed using historical forecast errors, assuming they are normally distributed and unbiased. The outturn for GDP growth in 2009 of less than $-2 \%$ is well below the $90 \%$ prediction interval of the resulting fan chart (Figure 5, Panel A), despite the width of the $90 \%$ interval exceeding 5 percentage points.

${ }^{11}$ A similar exercise compares the probit-model based methodology to parameterising fan charts to the approaches of the Bank of England and Riksbank, the two institutions that pioneered the use of fan charts (Turner and Chalaux, forthcoming). It is found that the Riksbank and Bank of England approaches imply that the GDP outturns for the United Kingdom and Sweden occurring at the time of the GFC were very much less likely than the probability of being struck down by lightning, whereas the GFC lies well within conventional prediction intervals of fan charts calibrated on (out-of-sample) probit model predictions.

12 To be clear, this exercise uses 'quasi-real-time' data that is the sample size of the current data set is constrained to the period that would have been available at the time of the forecasts. This is not the same as using 'real-time' data that was available at the time of the forecast. However, the difference between 'real-time' and 'quasi-real-time' data in this case is likely to be small as most of explanatory variables (such as interest rates, house prices, equity prices, etc.) are not subject to revision. An important exception where the analysis does use real-time data is for the unemployment gap for which the out-of-sample analysis is careful to use the estimates that were published at the same time as the publication of the forecasts for which the fan charts are computed. 
26. A second fan chart is computed using the probit methodology described above, but using the regressions based on pre-crisis data to parameterise the skew in the fan chart. At the time of the publication of the June 2008 forecast, using data that was available in the first quarter, the annualised risk of a downturn in 2009 in computed as $20 \%$, which implies a skew (the difference between the mean and mode) of three-quarter percentage points to the fan chart. There are a combination of factors underlying this high downturn probability at the beginning of 2008: a negative yield curve slope; the high level of the house-price-to-rent ratio; the more recent fall in real house prices and real share prices over the preceding year; a positive unemployment gap (indicating labour market overheating); and all against a background of sustained strong growth in OECD-wide real house prices. This degree of skew implies risks to the 2009 GDP forecast are tilted to the downside with the outturn for GDP growth being just within the $90 \%$ prediction interval (Figure 5, panel B).

27. The same exercise is then repeated for the December 2007 OECD forecast which covers a two-year horizon to 2009 . The accompanying commentary was prescient in emphasising downside risks: "The projection is subject to substantial downside risk as the financial turmoil and the housing slump may cause greater disruption to real activity than foreseen." The straw man fan chart for the December 2007 forecast, implies the 2008 outturn is just within the $50 \%$ prediction interval, but the 2009 outturn is well below the lower bound of the $90 \%$ confidence interval, again despite the overall width of the $90 \%$ band being more than 5 percentage points (Figure 6, panel A). Conversely, for a fan chart based on the (out-of-sample) probit model risk (Figure 6, panel B), the outturns for 2008 and 2009 are both close to the boundary of the $50 \%$ prediction interval. 
Figure 5. Fan charts for the June 2008 OECD forecast of the United States

(A) Calibrated using historical errors, assuming normality

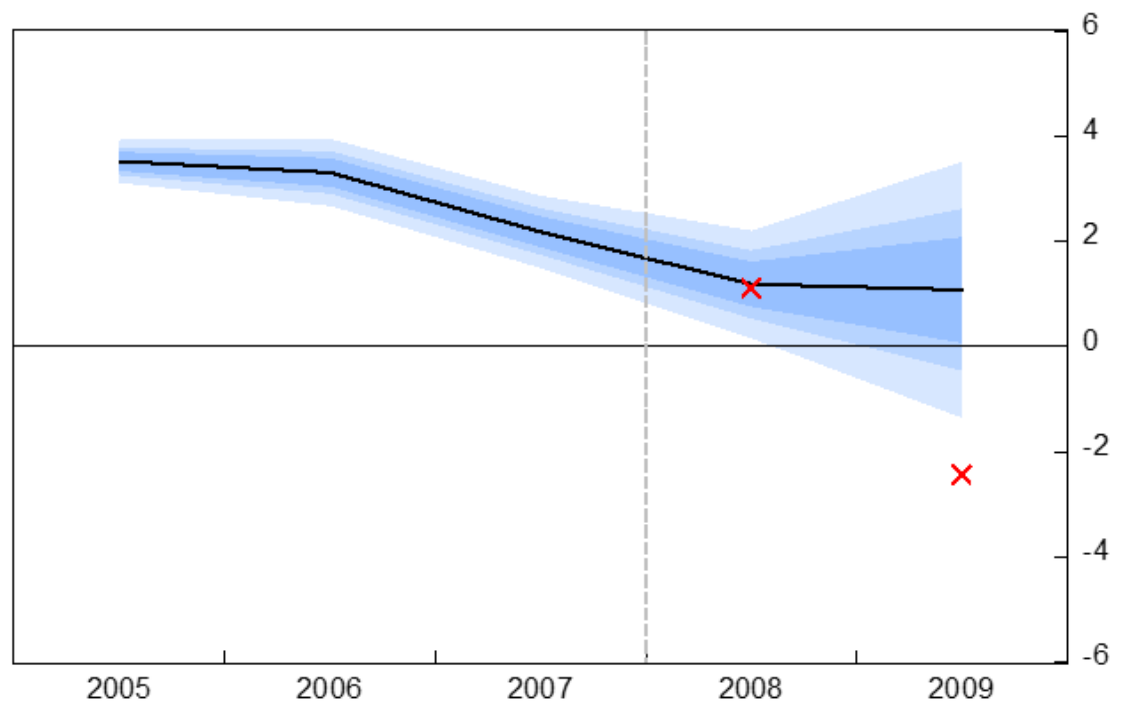

(B) Calibrated using probit models, allowing for asymmetry

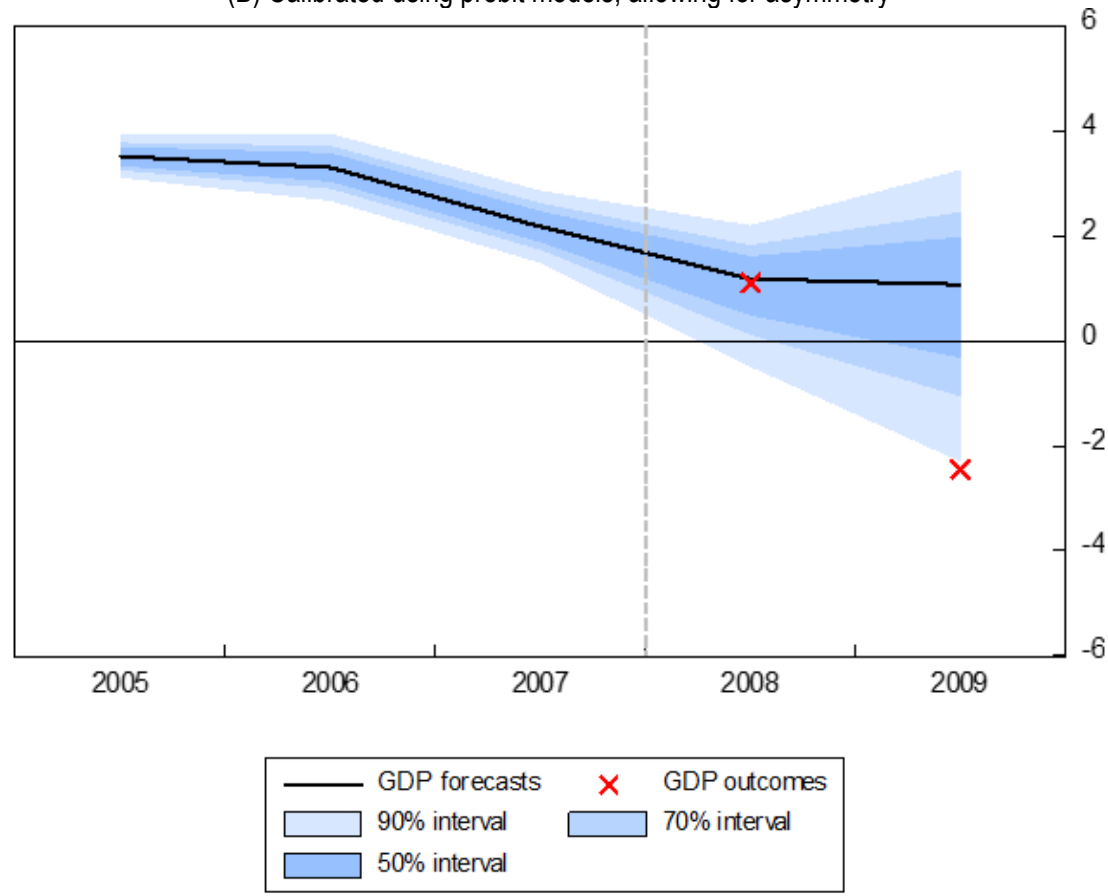

Note: Shaded blue areas show successively the $50 \%, 70 \%$ and $90 \%$ prediction intervals. The solid black line is the outturn up to 2007 and the projection for 2008 and 2009, as reported in the June 2008 Economic Outlook. The red crosses show the outturn according to the Economic Outlook published in the year following the first outturn data. The prediction intervals around the historical growth path reflect the extent to which historical estimates of GDP growth are subsequently revised. 
Figure 6. Fan charts for the December 2007 OECD forecast of the United States

(A) Calibrated using historical errors, assuming normality

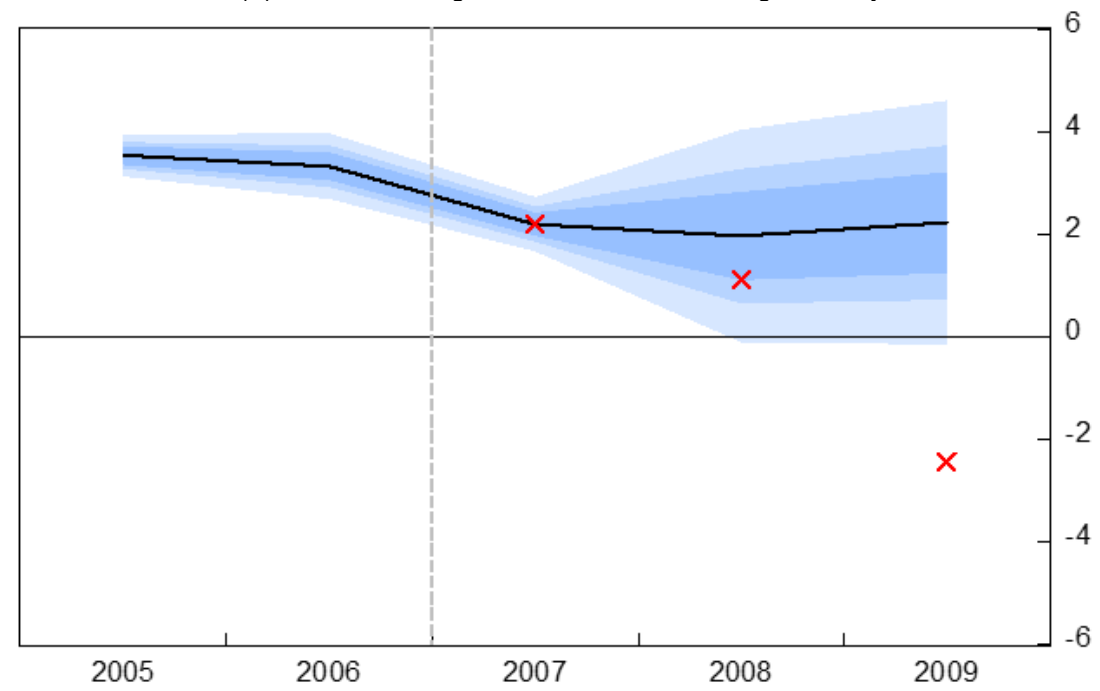

(B) Calibrated using probit models, allowing for asymmetry

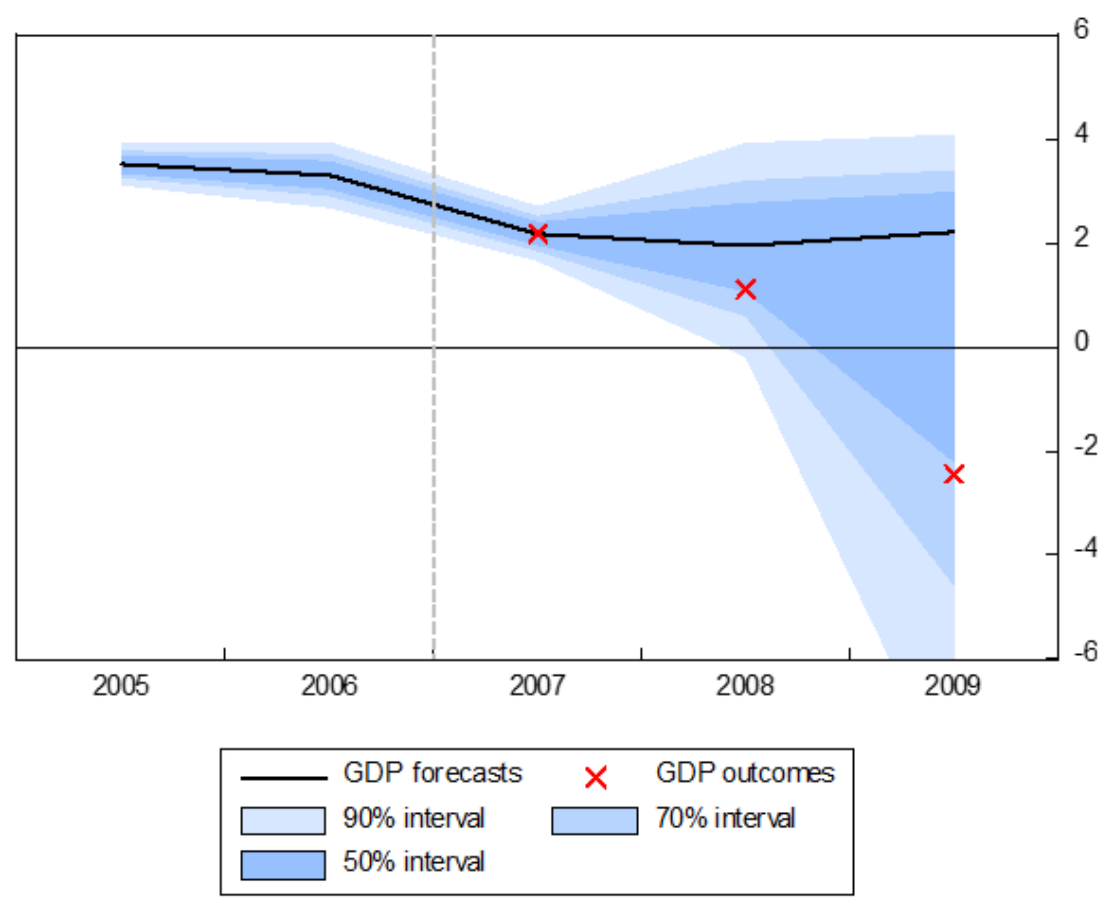

Note: Shaded blue areas show successively the $50 \%, 70 \%$ and $90 \%$ prediction intervals. The solid black line is the outturn up to 2006 and the projections for 2007, 2008 and 2009 are as reported in the December 2007 Economic Outlook. The red crosses show the outturn according to the Economic Outlook published in the year following the first outturn data. The prediction intervals around the historical growth path reflect the extent to which historical estimates of GDP growth are subsequently revised. 


\subsection{Pre-crisis fan charts for the other $G 7$ countries}

28. The same exercises of computing both benchmark and probit-based fan charts are repeated for the pre-crisis forecasts for the other G7 countries. In all cases, the published forecasts failed to predict the severity of the downturn in 2009. The commentary on risks in the December 2007 forecasts published in the OECD Economic Outlook No. 82 (EO82) appeared more aware of the downside risks than the June 2008 (EO83) forecasts; for five of the EO82 G7 country forecasts the accompanying commentary unambiguously identifies downside risks associated with financial markets and/or the international environment, whereas for the EO83 forecasts there were only two of the G7 countries for which this was the case; the editorial in EO82 emphasised that the probability distribution around the central scenario had "a fat tail to the downside", whereas the editorial in EO83 was entitled "After the Storm?".

29. All G7 GDP outturns for 2009 are below, and usually well below, the $90 \%$ prediction interval of the symmetrical benchmark fan charts computed for the June 2008 forecasts (Table 6, Panel A). On the other hand, fan charts computed using the probit-based downturn probabilities all have substantial negative skew and consequently the 2009 GDP growth outturns for all G7 countries, with the exceptions of Japan and Italy, fall within the 90\% prediction interval (Table 6, Panel A and Figure 7).

30. Repeating the exercise for the December 2007 forecasts, the probit-based fan charts again outperform the benchmark symmetrical fan charts. Thus, for six of the G7 countries the 2008 GDP outturns are within the $70 \%$ prediction interval of the probit-based fan chart, whereas this is the case for only two of the $\mathrm{G} 7$ countries using the benchmark symmetrical fan chart (Table 6, Panel B). For the 2009 GDP outturns, the probit-based fan charts represent a clear improvement on the benchmark fan charts in most cases, although only the 2009 outturns for the United States, Canada and the United Kingdom appear within the $90 \%$ prediction interval of the probit-based fan charts (Table 6, Panel C). The relatively poorer performance of the December 2007 probit-based fan charts compared to June 2008 vintages in terms of encompassing the 2009 outturns may be due to the longer forecast horizon. Nevertheless, all the December 2007 fan charts do exhibit substantial downward skew in 2008 and 2009 (Figure 8), which might have provided a useful policy signal, particularly given the simultaneous nature of these risks. 


\section{Figure 7. Probit-based fan charts for June 2008 OECD forecasts for other G7 countries}

(i) Japan

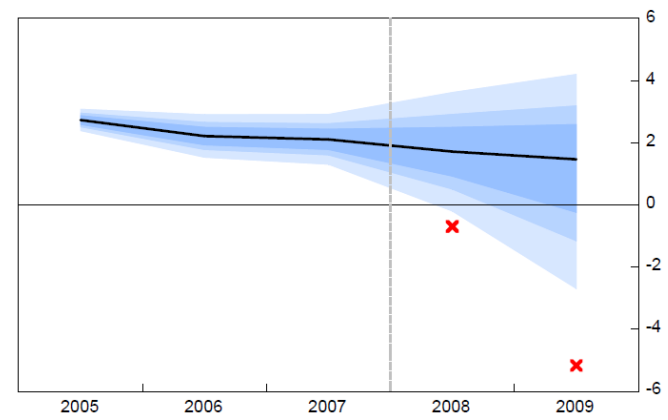

(iii) United Kingdom (ii) Germany

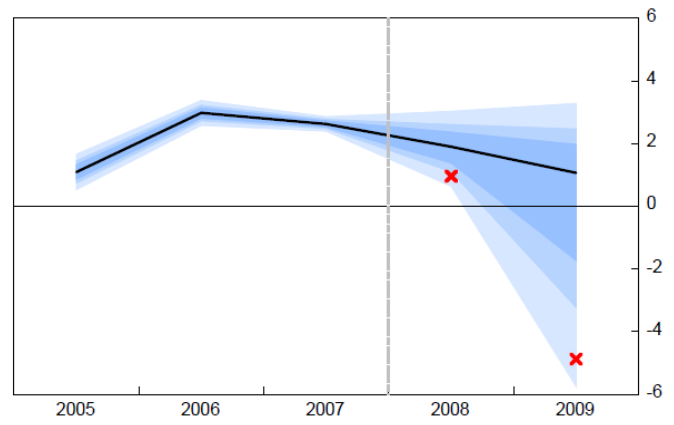

(iv) France

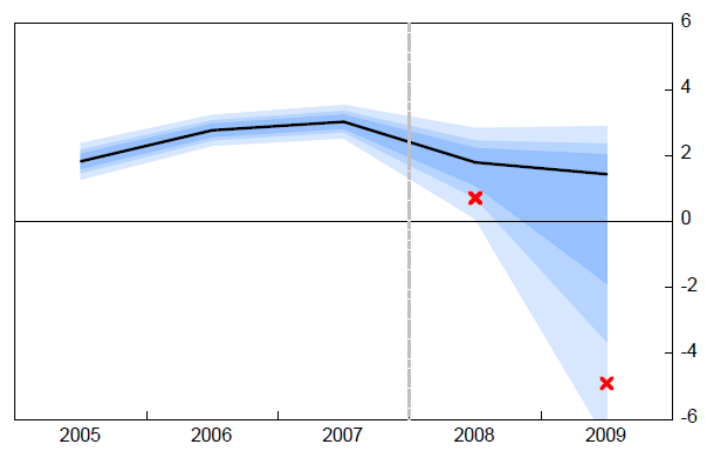

(v) Italy

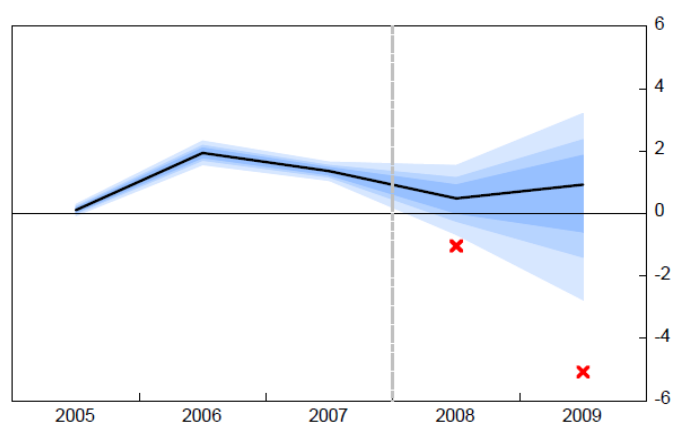

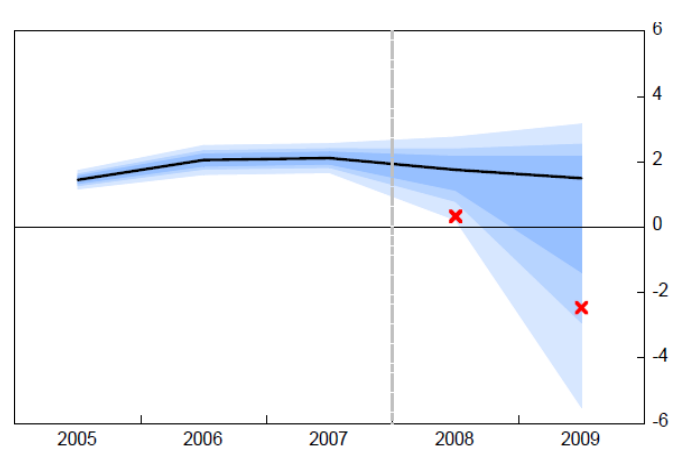

(vi) Canada

$\square$ GDP forecasts $\times$ GDP outcomes
$\square$ 90\% interval $\quad \square 70 \%$ interval
$\square$ 50\% interval

Note: All fan charts are computed using the probit model assessment of downturn risks. Shaded blue areas show successively the $50 \%, 70 \%$ and $90 \%$ prediction intervals. The solid black line is the outturn up to 2007 and the projections for 2008 and 2009 are as reported in the June 2008 Economic Outlook. The red crosses show the outturn according to the Economic Outlook published in the year following the first outturn data. The prediction intervals around the historical growth path reflect the extent to which historical estimates of GDP growth are subsequently revised. 
Figure 8. Probit-based fan charts for December 2007 OECD forecasts for other G7 countries

(i) Japan

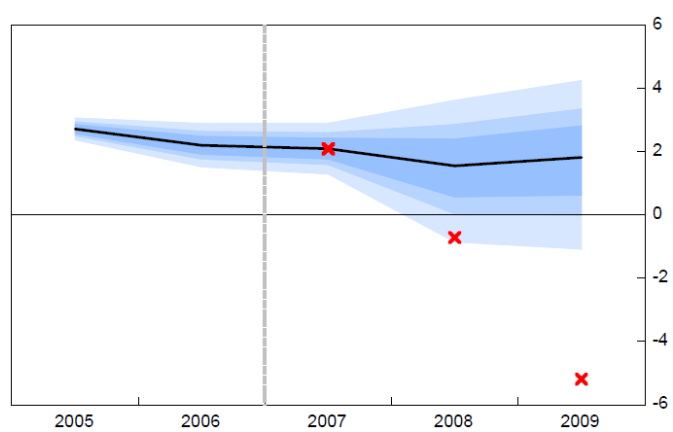

(iii) United Kingdom

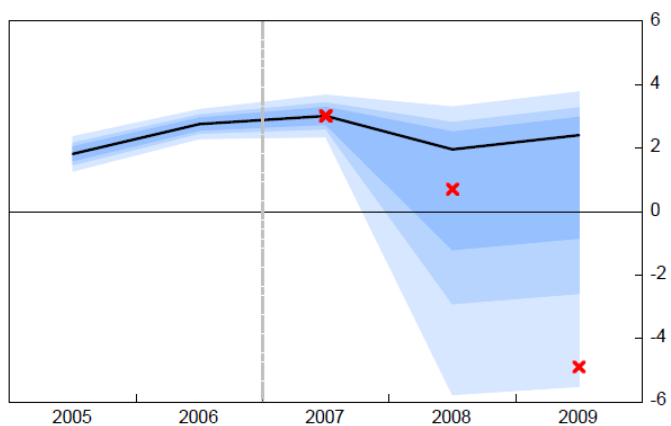

(v) Italy

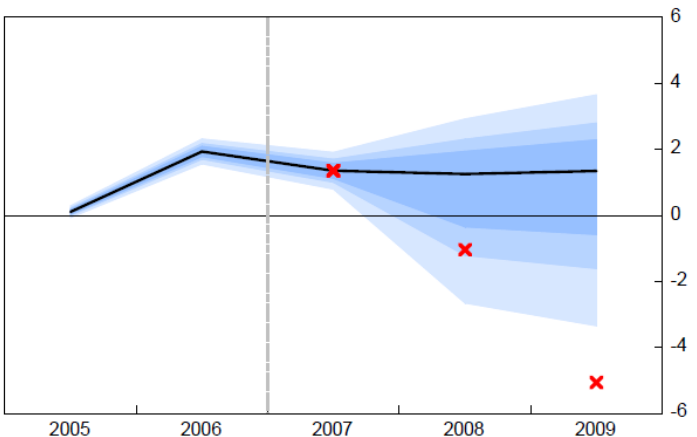

(ii) Germany

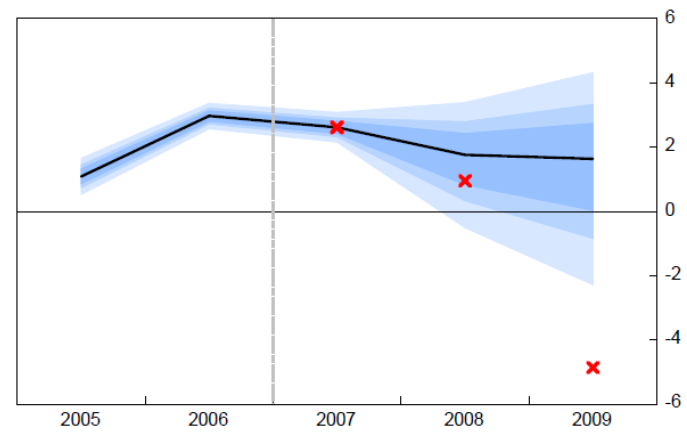

(iv) France

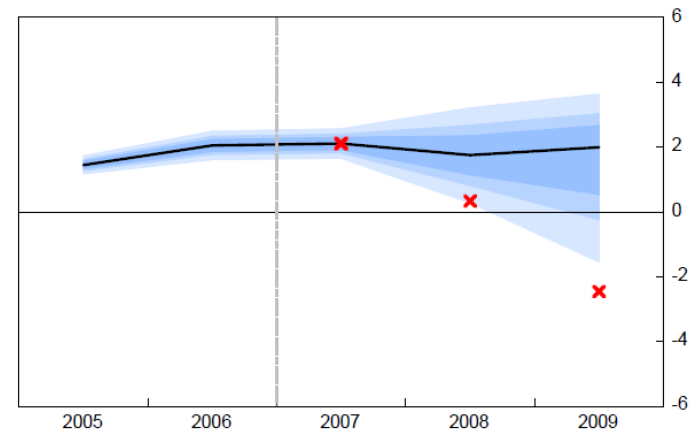

(vi) Canada

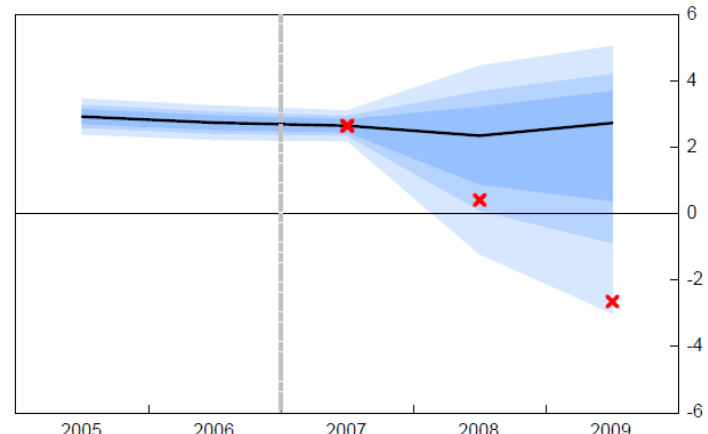

$\square$ GDP forecasts $\times$ GDP outcomes
$\square 90 \%$ interval $\quad \square 70 \%$ interval
$\square 50 \%$ interval

Note: All fan charts are computed using the probit model assessment of downturn risks. Shaded blue areas show successively the $50 \%, 70 \%$ and $90 \%$ prediction intervals. The solid black line is the outturn up to 2006 and the projections for 2007, 2008 and 2009 are as reported in the December 2007 Economic Outlook. The red crosses show the outturn according to the Economic Outlook published in the year following the first outturn data. The prediction intervals around the historical growth path reflect the extent to which historical estimates of GDP growth are subsequently revised. 
Table 6. The position of Global Financial Crisis G7 GDP outturns in pre-crisis fan charts

(A) Outturns for 2009 evaluated against fan charts for June 2008 EO forecasts

\begin{tabular}{|lccccccc|}
\hline Prediction interval & USA & JPN & DEU & GBR & FRA & ITA & CAN \\
\hline $0-50 \%$ & & & & & & & \\
$50-70 \%$ & & & & & P & & \\
$70-90 \%$ & P & & P & P & & & P \\
$90-99 \%$ & S & P & & & & P & S \\
$99 \%-99.9 \%$ & & S & & & S & & \\
$99.9 \%+$ & & & S & S & & S & \\
\hline
\end{tabular}

(B) Outturns for 2008 evaluated against fan charts for December 2007 EO forecasts

\begin{tabular}{|lccccccc|}
\hline Prediction interval & USA & JPN & DEU & GBR & FRA & ITA & CAN \\
\hline $0-50 \%$ & P & & P S & P & & & \\
$50-70 \%$ & S & P & & & & P & P \\
$70-90 \%$ & & S & & S & P S & & S \\
$90-99 \%$ & & & & & & S & \\
$99 \%-99.9 \%$ & & & & & & & \\
$99.9 \%+$ & & & & & & & \\
\hline
\end{tabular}

(C) Outturns for 2009 evaluated against fan charts for December 2007 EO forecasts

\begin{tabular}{|lccccccc|}
\hline Prediction interval & USA & JPN & DEU & GBR & FRA & ITA & CAN \\
\hline $0-50 \%$ & & & & & & & \\
$50-70 \%$ & P & & & & & & \\
$70-90 \%$ & & & & P & & & P \\
$90-99 \%$ & & & & & P & & \\
$99 \%-99.9 \%$ & S & P S & P & & S & P & \\
$99.9 \%+$ & & & S & S & & S & S \\
\hline
\end{tabular}

Note: The GDP growth outturns are calculated from the data published in the June 2010 OECD Economic Outlook. "S" denotes the position in a symmetrical fan chart calculated from historical RMSEs assuming historical forecast errors are normally distributed. "P" denotes the position in a fan chart calibrated using the probit-models estimated on a pre-crisis sample (see text for details). 


\section{Designing a fan chart for OECD-wide growth}

31. This section extends the probit methodology to generate a fan chart around forecasts of OECD-wide GDP growth, while still linking it to downturn risks in individual major OECD countries in order ensure some degree of consistency. ${ }^{13}$

32. One difference in the approach for the aggregate OECD compared to that for individual OECD countries is that the dependent variable is specified as a severe growth slowdown, rather than a severe absolute downturn during which growth in GDP per capita is negative for a sustained period. The rationale for this difference is that trend growth in OECD-wide GDP per capita has declined considerably over the estimation period; ${ }^{14}$ a five-year moving average of OECD GDP per capita has declined from more than $4 \frac{1}{2}$ per cent per annum at the beginning of the1970s to less than $2 \%$ per annum now. Thus, any given shock is much more likely to generate negative GDP per capita growth now than in previous decades. A severe growth slowdown episode is therefore defined relative to trend growth (taken to be a 5-year moving average), such that it begins and ends with a quarter in which annualised GDP per capita is at least $1 \%$ point less than trend growth and, in between the start and end quarters, the loss in cumulative GDP per capita relative to the trend is at least $2 \frac{1}{2}$ percentage points. Defined in this way there are six severe OECD-wide growth slowdown episodes: 1973Q3-75Q1; 1979Q2-80Q2; 1981Q2-82Q4; 1990Q3-93Q1; 2000Q3-01Q4 and 2007Q3-09Q1.

33. To compute an OECD-wide fan chart the same probit-based methodology is followed, but the weighted average of the downturn risk in the major OECD countries at an horizon of $n$ quarters $(n=2,4,6$ or 8$)$ is included as an explanatory variable in the OECD-wide probit equation at that same horizon of $n$ quarters (Table 7). The inclusion of this variable, which is always highly statistically significant, provides a degree of consistency with risks in the individual country models. In addition, the OECD-wide probit equations include other explanatory variables that are found to be significant: a measure of the weighted average of yield curve slope in a selection of major OECD countries ${ }^{15}$ is included at the 4 quarter horizon and the OECD-wide output gap is included at 2,6 and 8 quarter horizons.

34. The parameterisation of the fan charts relies, as before, on weighted combinations of predicted slowdown probabilities being correlated with past forecast errors; more specifically, it assumes the greater the probability of a slowdown, the greater the tendency to over-predict growth. Regressions of forecast errors of OECD-wide GDP growth on the slowdown probabilities bear out this association, with the coefficient on the slowdown probabilities being large and statistically significant at all forecast horizons (Table 8). Moreover, the intercept term in these regressions is typically small and statistically insignificant, suggesting that when slowdowns risks are negligible, then forecasts are unbiased.

\footnotetext{
${ }^{13}$ The IMF have been publishing fan charts around their year-ahead global growth forecasts in the World Economic Outlook since 2006 and a description of their methodology is provided by IMF (2009).

14 The rationale is similar to that explaining the different downturn definition for Japan as compared to other G7 countries.

15 The yield curve slope variable is taken as a GDP-weighted average of the yield curve slope of the United States, Japan, Germany and the United Kingdom.
} 
Table 7. Probit regressions of a severe slowdown in OECD-wide growth

\begin{tabular}{|c|c|c|c|c|c|}
\hline \multirow{3}{*}{$\begin{array}{l}\text { Binary dependent variable }{ }^{1} \text { : } \\
1=\text { severe downturn, } 0=\text { otherwise }\end{array}$} & \multirow{3}{*}{$\begin{array}{l}\text { Standard } \\
\text { deviation }^{2}\end{array}$} & \multicolumn{4}{|c|}{ Probit regression at horizon of $Q$ quarters } \\
\hline & & $Q=2$ & $Q=4$ & $Q=6$ & $Q=8$ \\
\hline & & $\begin{array}{l}\text { 1976Q1- } \\
\text { 2018Q3 }\end{array}$ & $\begin{array}{l}\text { 1976Q3- } \\
\text { 2018Q3 }\end{array}$ & $\begin{array}{l}\text { 1976Q4- } \\
\text { 2018Q3 }\end{array}$ & $\begin{array}{l}\text { 1977Q2- } \\
\text { 2018Q3 }\end{array}$ \\
\hline Constant & & $-1.54^{\star * *}$ & $-1.58^{\star \star *}$ & $-1.58^{\star * *}$ & $-1.31^{* * *}$ \\
\hline OECD yield curve ${ }^{3}$ & 1.28 & & $-0.29^{* *}$ & & \\
\hline OECD-wide output gap & 1.67 & $0.35^{\star * *}$ & & $0.22^{*}$ & $0.26^{*}$ \\
\hline Weighted downturn probability in $\mathrm{G} 7^{4}$ & & $5.48^{* * *}$ & $4.10^{* * *}$ & $5.11^{* \star *}$ & $3.70^{* * *}$ \\
\hline McFadden R-sqd & & 0.47 & 0.38 & 0.44 & 0.36 \\
\hline$\%$ of correct predictions ${ }^{5}$ & & $85 \%$ & $84 \%$ & $83 \%$ & $80 \%$ \\
\hline Downturns & & $89 \%$ & $83 \%$ & $86 \%$ & $86 \%$ \\
\hline Non-downturns & & $84 \%$ & $84 \%$ & $82 \%$ & $78 \%$ \\
\hline
\end{tabular}

Notes

1) The dependent variable is a binary variable taking the value of one in a severe growth slowdown episode and zero otherwise. See text for the definition of a severe growth slowdown episode.

2) The standard deviation of the explanatory variable over the full sample.

3) A GDP-weighted average of the slope of the yield curve in the United States, Japan, Germany and the United Kingdom.

4) Takes the GDP-weighted average of a severe downturn in each of the G7 countries.

5) Predictions categorised according to a $15 \%$ probability threshold.

For the probit regression at a horizon of $\mathrm{Q}$ quarters $(\mathrm{Q}=2,4,6$ or 8$)$ the output gap enters the equations lagged by $Q$ quarters and the slope of the yield curve with a lag of (Q-1) quarters. The weighted downturn probability variable enters the equation contemporaneously, but is itself a prediction based on data lagged by $\mathrm{Q}$ quarters. Statistical significance of coefficients at the $1 \%, 5 \%$ and $10 \%$ levels are denoted by '***', '**' and '*”.

Table 8. Regressions of OECD GDP growth forecast errors on slowdown probabilities

\begin{tabular}{lcccc}
\hline & \multicolumn{4}{c}{ Dependent variable: forecast error, $\epsilon_{\mathrm{t}}{ }^{(\mathrm{s}, \mathrm{t+i})}$} \\
\cline { 2 - 5 } Forecast published in & Spring & Autumn & Spring & Autumn \\
Forecast horizon & curent-year & year-ahead & year-ahead & 2-years-ahead \\
Sample period & $1981-2017$ & $1980-2017$ & $1982-2017$ & $1989-2017$ \\
\hline Intercept term, $\alpha$ & 0.13 & 0.26 & 0.22 & -0.01 \\
Downturn probability P, $\beta$ & $-0.57^{* *}$ & $-1.47^{* * *}$ & $-3.40^{* * *}$ & $-2.65^{\star * *}$ \\
R-sqd adjusted & 0.12 & 0.20 & 0.34 & 0.24 \\
\hline
\end{tabular}

Note: Table reports the coefficient estimates from regressions $\epsilon_{t}^{s, t+i}=\alpha^{s, t+i}+\beta^{s, t+i} P_{t}^{s, t+i}$, explaining annual forecast errors, $\epsilon_{t}^{s, t+i}$, distinguishing whether the associated forecasts were published in the Spring $(s=S)$ or Autumn $(s=A)$ of year $t$ and for which year $(t+i)$ the forecasts were made (where $\mathrm{i}=0,1$ or 2 ). These errors are then explained in terms of the corresponding annualised probability of a slowdown, $P_{t}^{s, t+i}$, derived from the predicted quarterly probit model probabilities of the equations in Table 7. Statistical significance of coefficients at the $1 \%, 5 \%$ and $10 \%$ levels are denoted by '***', '**' and '*', respectively. 
35. The same out-of-sample test is then performed using re-estimates of the equations specified in Tables 7 and 8, but over a pre-crisis sample period, to see how well they encompass the extreme outturns of the Global Financial Crisis. For the June 2008 forecast, the 2009 outturn is within the $90 \%$ prediction interval of a fan chart based on the probit model parametrisation, but falls well outside a fan chart constructed under the assumption that forecast errors are normally distributed (Figure 9, panels A and B). For the December 2007 forecast, the probit-based fan chart does exhibit considerable downward skew, although the 2009 outturn is just outside the $90 \%$ prediction interval. Nevertheless, the probitbased fan chart performs much better than the symmetric fan chart (Figure 9, panels C and D) and the degree of negative skew in the fan chart would still have provided a platform for a strong policy message regarding future risks.

\section{Figure 9. Fan charts for pre-crisis forecasts of OECD-wide GDP growth} June 2008 forecast

(A) Using historical errors, assuming normality

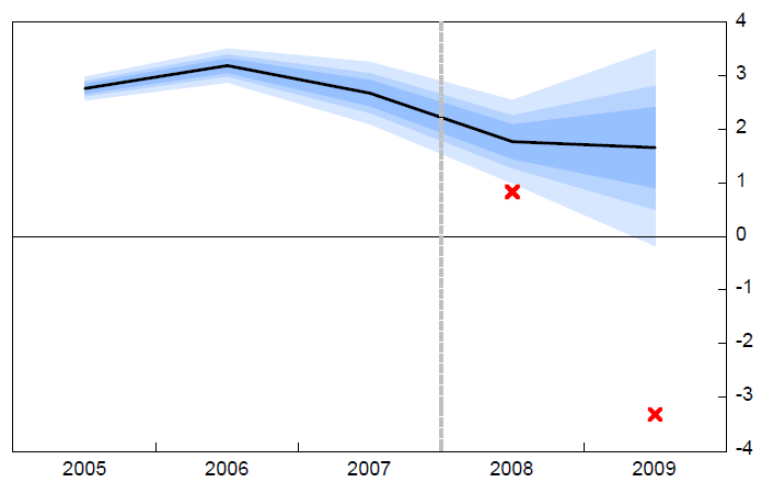

(B) Using probit models, allowing for asymmetry

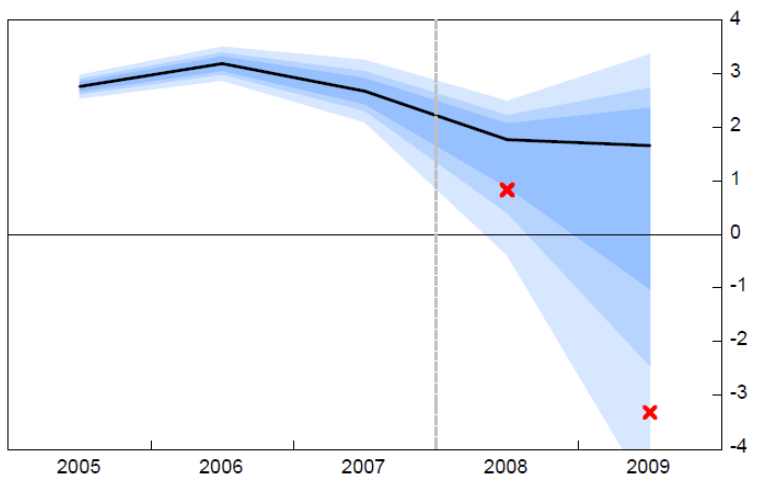

December 2007 forecast

(C) Using historical errors, assuming normality

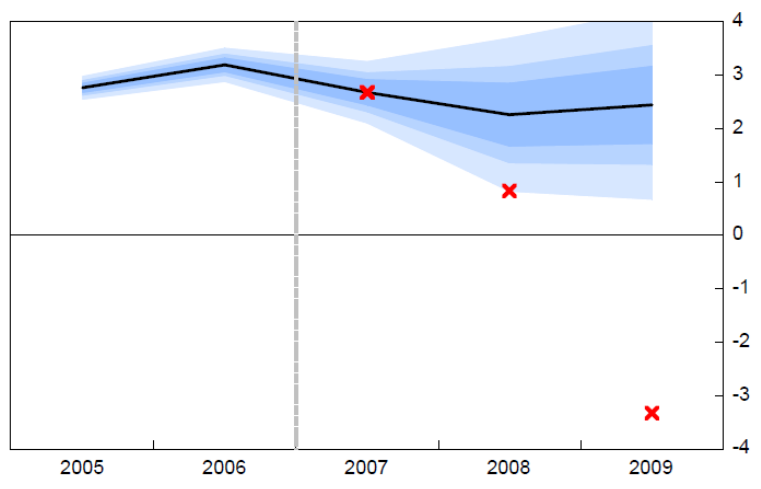

(D) Using probit models, allowing for asymmetry

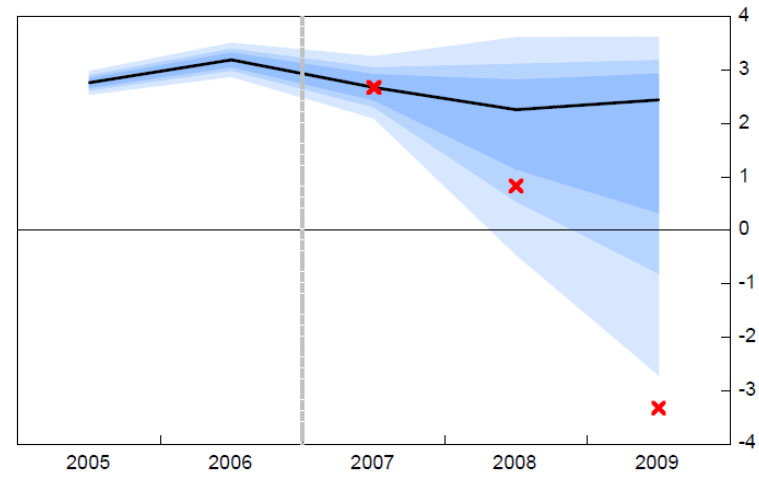

Note: Shaded blue areas show successively the $50 \%, 70 \%$ and $90 \%$ prediction intervals. The solid black line shows the outturns prior to the year in which the forecast was published and thereafter the projections, as reported in the June 2008 Economic Outlook (panels A and B) and December 2007 Economic Outlook (panels C and D). The red crosses show the outturn according to the Economic Outlook published in the year following the first outturn data. The prediction intervals around the historical growth path reflect the extent to which historical estimates of GDP growth are subsequently revised. 


\section{References}

Abreu, I. (2011), "International Organisations' vs Private Analysts' Forecasts: An Evaluation", Banco de Portugal Working Papers, 20/2011, July.

Adrian, T., R. Crump, and E. Moench (2013), "Pricing the Term Structure with Linear Regressions", Journal of Financial Economics, 110, no. 1, October.

Bank of England (2005), "Assessing the MPC's Fan Charts", Bank of England Quarterly Bulletin.

Blix, M. and P. Sellin (1998), "Uncertainty Bands for Inflation Forecasts", Sveriges Riksbank Working Paper Series, No. 65.

Boero, G., Smith, J. and Wallis, K. F. (2015), "The Measurement and Characteristics of Professional Forecasters' Uncertainty", Journal of Applied Econometrics, vol. 30: 1029-1046. doi: 10.1002/jae.2400.

Britton, E., P. Fisher and J. Whitley (1997), "Asymmetry, Risks and a Probability Distribution of Inflation", Bank of England Quarterly Bulletin.

Buckles, K. D. Hugerman and Steven Lugauer (2018), "Is Fertility a Leading Economic Indicator?", NBER Working Paper No. 24355, February.

Buiter, W. and M. Miller (1981), "The Thatcher Experiment: The First Two Years", Brookings Papers on Economic Activity, Vol. 2.

Casella, G. and R. Berger (2002), Statistical inference, Second Edition, Duxbury Advanced Series.

Cross, P. and D. Wyman (2011), "The Relationship between Monthly, Quarterly and Annual Growth Rates", Canadian Economic Observer, June.

Dovern, J. and C. Zieglar (2008), "Predicting Growth Rates and Recession. Assessing US Leading Indicators Under Real Time Conditions", Working Paper 1397, Kiel University.

Estrella, A. (2007), "Why does the Yield Curve Predict Output and Inflation?" Economic Journal, 115:722-44.

Estrella, A and F. S. Miskin (1997), "The Predictive Power of the Term Structure of Interest Rates in Europe and the United States: Implications for the European Central Bank", European Economic Review, 41:1375-1401.

Estrella, A., A. Rodrigues and S. Schich (2003), "How Stable is the Predictive Power of the Yield Curve? Evidence from Germany and the United States", Review of Economics and Statistics, 85:629-644.

Fildes, R. and Steckler, (2002), "The state of macroeconomic forecasting", Journal of Macroeconomics, 24(2), pp. 435-468.

Fornari, F. and W. Lemke (2010), "Predicting Recession Probablities with Financial Variables over Multiple Horizons", ECB Working Paper Series, No. 1255, October. 
Hermansen, M and O. Röhn (2016), "Economic resilience: The usefulness of early warning indicators in OECD countries", OECD Journal: Economic Studies, No. 1, Vol. 2016, Issue, 1, pp. 9-35. OECD Publishing, Paris. DOI: http://dx.doi.org/10.1787/eco_studies-2016-5jg2ppjrd6r3

IMF (2009), "Fan Chart for Global Growth", Annex 1.2, IMF World Economic Outlook, April.

John, S. (1982), "The three-parameter two-piece normal family of distributions and its fitting", Communications in Statistics - Theory and Methods, 11(8), pp. 879-885. DOI: http://dx.doi.org/10.1080/03610928208828279.

Kergozou, N. and D. Turner (forthcoming), "Using Probit Models of Downturn Risk to Calibrate GDP Fan Chart for New Zealand", OECD Economics Department Working Papers.

Loungani, P. (2001), "How Accurate are Private Sector Forecasts? Cross-Country Evidence from Consensus Forecasts of Output Growth", International Journal of Forecasting, 17(3), pp. 410-432

OECD (2007), OECD Economic Outlook, No. 82, Vol. 2007/2, OECD Publishing, Paris. DOI: https://doi.org/10.1787/16097408

OECD (2008), OECD Economic Outlook, No. 83, Vol. 2008/1, June, OECD Publishing, Paris. DOI: http://dx.doi.org/10.1787/eco_outlook-v2008-1-en

Ollivaud, P., et al. (2016), "Forecasting GDP during and after the Great Recession: A contest between small-scale bridge and large-scale dynamic factor models", OECD Economics Department Working Papers, No. 1313, OECD Publishing, Paris, https://doi.org/10.1787/5jlv2jj4mw40-en.

Pain, N. and C. Lewis (2014), "Lessons Learned from OECD Forecasts During and after the Financial Crisis", OECD Journal: Economic Studies, No. 5, Vol. 2104, Issue, 1, pp. 939, OECD Publishing, Paris. DOI: http://dx.doi.org/10.1787/eco_studies-2014$5 \mathrm{j} x \mathrm{rcm} 2 \mathrm{glc} 7 \mathrm{j}$

Romei, V. and K. Fray (2018), "IMF shows poor track record at forecasting recessions", Financial Times, April 9.

Rusticelli, E., D. Turner and M. Cavalleri (2015), "Incorporating Anchored Inflation Expectations in the Phillips Curve and in the Derivation of OECD Measures of Equilibrium Unemployment", OECD Economics Department Working Papers, No. 1231, OECD Publishing, Paris. DOI: http://dx.doi.org/10.1787/5js1gmq551wd-en

Sveriges Riksbank (2007), "Calculation Method for Uncertainty Bands”, Monetary Policy Report, 2007:1

Turner D. and T. Chalaux (forthcoming), "Calibrating Fan Charts Using Probit Models with a Comparison to the Bank of England and Riksbank Approaches", OECD Economics Department Working Papers.

Turner, D. (2017), "Designing Fan Charts for GDP Growth Forecasts to Better Reflect Downturn Risks, OECD Economics Working Papers, No. 1428, OECD Publishing, Paris. DOI: http://dx.doi.org/10.1787/e86flbfc-en 
Wallis, K. F. (2014), "The Two-Piece Normal, Binormal, or Double Gaussian distribution: Its Origin and Rediscoveries", Statistical Science, Vol. 29, No. 1, pp. 106-112, https://projecteuclid.org/euclid.ss/1399645739

Wallis, K. F. (2004), "An Assessment of Bank of England and National Institute Forecast Uncertainties", National Institute Economic Review, No. 189, July.

Wallis K F. (1999), "Asymmetric Density Forecasts of Inflation and the Bank of England's Fan Chart", National Institute Economic Review, January.

World Bank (2016), "Quantifying Uncertainties in Global Growth Forecasts”, Special Focus 2 in Global Economic Prospects, June. 


\section{Annex A. Detailed probit model estimation results}

Table A1. Detailed probit regressions explaining downturn probabilities for the G7 economies (i) United States

\begin{tabular}{|c|c|c|c|c|c|}
\hline \multirow{3}{*}{$\begin{array}{l}\text { Binary dependent variable }{ }^{1} \text { : } \\
1=\text { severe downturn, } 0=\text { otherwise }\end{array}$} & \multirow{3}{*}{$\begin{array}{l}\text { Standard } \\
\text { deviation }\end{array}$} & \multicolumn{4}{|c|}{ Probit regression at horizon of $Q$ quarters } \\
\hline & & $Q=2$ & $Q=4$ & $\mathrm{Q}=6$ & $Q=8$ \\
\hline & & $\begin{array}{l}\text { 1971Q4- } \\
\text { 2018Q3 }\end{array}$ & $\begin{array}{l}\text { 1971Q2- } \\
\text { 2018Q3 }\end{array}$ & $\begin{array}{l}\text { 1971Q4- } \\
2018 Q 3\end{array}$ & $\begin{array}{l}\text { 1972Q2- } \\
\text { 2018Q3 }\end{array}$ \\
\hline Constant & & $-5.90^{\star * \star}$ & $-7.73^{\star * *}$ & $-6.76^{\star * *}$ & $-6.10^{* * \star}$ \\
\hline Yield curve slope ${ }^{3}$ & 1.98 & $-0.65^{\star * *}$ & $-0.43^{* * * *}$ & $-0.34^{* * *}$ & $-0.22^{\star * *}$ \\
\hline Unemployment gap ${ }^{4}$ & 1.48 & $0.77^{* * *}$ & & $0.46^{* *}$ & $0.42^{* *}$ \\
\hline \multicolumn{6}{|l|}{ Real share prices } \\
\hline 1-year annual growth & 15.23 & $-0.04^{* *}$ & & & \\
\hline \multicolumn{6}{|l|}{ Real house prices } \\
\hline 1-year annual growth & 4.03 & $-0.21^{* * *}$ & & & \\
\hline \multicolumn{6}{|l|}{ House price-to-rent ratio } \\
\hline Level,1-year average & 9.27 & $0.04^{*}$ & $0.06^{* * *}$ & $0.05^{\star * *}$ & $0.05^{\star * *}$ \\
\hline McFadden R-sqd & & 0.67 & 0.41 & 0.41 & 0.30 \\
\hline$\%$ of correct predictions ${ }^{5}$ & & $90 \%$ & $87 \%$ & $84 \%$ & $78 \%$ \\
\hline Downturns & & $92 \%$ & $81 \%$ & $89 \%$ & $81 \%$ \\
\hline Non-downturns & & $89 \%$ & $88 \%$ & $83 \%$ & $78 \%$ \\
\hline
\end{tabular}

(ii) Japan

\begin{tabular}{|c|c|c|c|c|c|}
\hline \multirow[b]{2}{*}{$\begin{array}{l}\text { Binary dependent variable }{ }^{1} \text { : } \\
1=\text { severe downturn, } 0=\text { otherwise }\end{array}$} & \multirow[b]{2}{*}{$\begin{array}{l}\text { Standard } \\
\text { deviation }^{2}\end{array}$} & \multicolumn{4}{|c|}{ Probit regression at horizon of $Q$ quarters } \\
\hline & & $\begin{array}{c}\mathrm{Q}=2 \\
1976 \mathrm{Q} 1- \\
2018 \mathrm{Q} 3\end{array}$ & $\begin{array}{c}Q=4 \\
1976 Q 3- \\
2018 Q 3\end{array}$ & $\begin{array}{c}Q=6 \\
1976 Q 4- \\
2018 Q 3\end{array}$ & $\begin{array}{c}Q=8 \\
1977 Q 2- \\
2018 Q 3\end{array}$ \\
\hline Constant & & $-2.83^{\star \star *}$ & $-1.77^{\star \star \star}$ & $-3.54^{* \star *}$ & $-7.73^{\star \star \star}$ \\
\hline \multicolumn{6}{|l|}{ Capacity utilisation rate } \\
\hline 1-year annual change & 10.27 & $-0.07^{* * \star}$ & $-0.16^{* * *}$ & & \\
\hline Level & 11.30 & $0.06^{* *}$ & $0.16^{* * *}$ & & \\
\hline \multicolumn{6}{|l|}{ House price-to-rent ratio } \\
\hline 5-year annual average growth & 3.19 & & & & $0.28^{* * *}$ \\
\hline \multicolumn{6}{|l|}{ Bank credit-to-GDP ratio } \\
\hline 1-year annual change & 2.68 & $-0.40^{\star * \star}$ & $-0.23^{\star *}$ & & \\
\hline \multicolumn{6}{|l|}{ Credit-to-GDP ratio } \\
\hline 5 -year annual average change & 4.10 & $0.14^{* \star *}$ & & $0.13^{* \star *}$ & \\
\hline \multicolumn{6}{|l|}{ OECD credit-to-GDP } \\
\hline 5-year annual average change & 1.32 & $0.83^{\star *}$ & $0.47^{*}$ & & \\
\hline \multicolumn{6}{|l|}{ OECD real house prices } \\
\hline 5-year annual average growth & 2.02 & & & $0.75^{\star \star \star}$ & $1.95^{\star \star \star}$ \\
\hline McFadden R-sqd & & 0.58 & 0.60 & 0.52 & 0.70 \\
\hline$\%$ of correct predictions ${ }^{4}$ & & $90 \%$ & $91 \%$ & $90 \%$ & $93 \%$ \\
\hline Downturns & & $88 \%$ & $94 \%$ & $88 \%$ & $94 \%$ \\
\hline Non-downturns & & $90 \%$ & $90 \%$ & $91 \%$ & $93 \%$ \\
\hline
\end{tabular}


(iii) Germany

\begin{tabular}{|c|c|c|c|c|c|}
\hline \multirow{3}{*}{$\begin{array}{l}\text { Binary dependent variable }{ }^{1} \text { : } \\
1=\text { severe downturn, } 0=\text { otherwise }\end{array}$} & \multirow{3}{*}{$\begin{array}{l}\text { Standard } \\
\text { deviation }^{2}\end{array}$} & \multicolumn{4}{|c|}{ Probit regression at horizon of $Q$ quarters } \\
\hline & & $Q=2$ & $Q=4$ & $Q=6$ & $Q=8$ \\
\hline & & \multicolumn{4}{|c|}{ 1973Q4-2018Q3 1974Q2-2018Q3 1974Q4-2018Q3 1975Q2-2018Q3 } \\
\hline Constant & & $-1.16^{* * *}$ & $-1.23^{* * *}$ & $-1.80^{* * *}$ & $-2.81^{* * *}$ \\
\hline Yield curve slope $^{3}$ & 1.46 & $-0.34^{\star * *}$ & $-0.95^{* * *}$ & $-0.53^{\star * *}$ & \\
\hline Unemployment gap ${ }^{4}$ & 0.84 & $0.60^{* *}$ & $0.94^{* * *}$ & $0.94^{\star * *}$ & $1.89^{* * *}$ \\
\hline \multicolumn{6}{|l|}{ Real share prices } \\
\hline 3-year annual average growth & 11.71 & & & & $0.07^{* *}$ \\
\hline \multicolumn{6}{|l|}{ Euro Area real house prices } \\
\hline 1 to 3-year annual average growth difference & 2.05 & $-0.34^{* * *}$ & $-0.29^{* *}$ & & \\
\hline 3-year annual average growth & 2.95 & & & $0.26^{* * *}$ & $0.38^{* * *}$ \\
\hline McFadden R-sqd & & 0.46 & 0.68 & 0.60 & 0.61 \\
\hline$\%$ of correct predictions ${ }^{5}$ & & $87 \%$ & $92 \%$ & $91 \%$ & $92 \%$ \\
\hline Downturns & & $93 \%$ & $93 \%$ & $92 \%$ & $96 \%$ \\
\hline Non-downturns & & $86 \%$ & $91 \%$ & $91 \%$ & $91 \%$ \\
\hline
\end{tabular}

(iv) United Kingdom

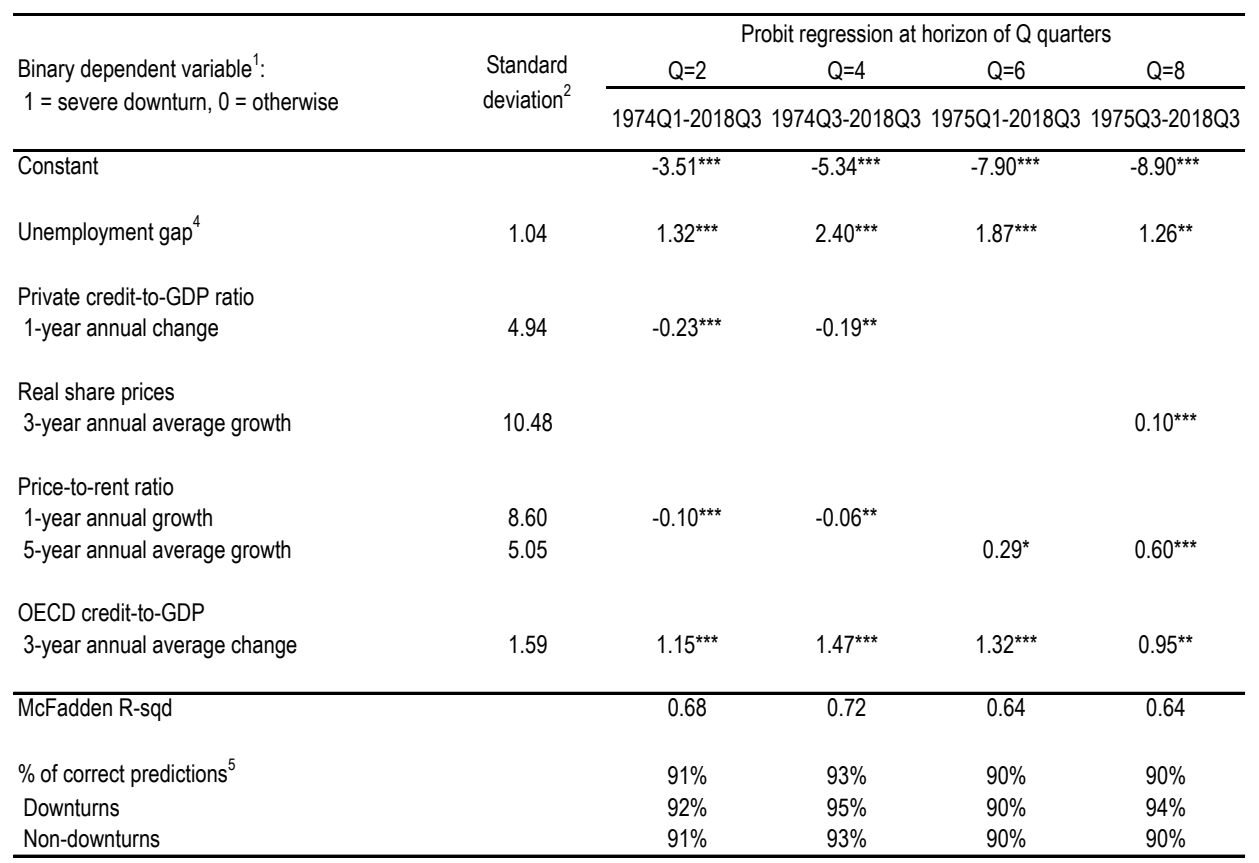


(v) France

\begin{tabular}{|c|c|c|c|c|c|}
\hline \multirow{3}{*}{$\begin{array}{l}\text { Binary dependent variable }{ }^{1} \text { : } \\
1=\text { severe downturn, } 0=\text { otherwise }\end{array}$} & \multirow{3}{*}{$\begin{array}{l}\text { Standard } \\
\text { deviation }\end{array}$} & \multicolumn{4}{|c|}{ Probit regression at horizon of $Q$ quarters } \\
\hline & & $\mathrm{Q}=2$ & $\mathrm{Q}=4$ & $\mathrm{Q}=6$ & $Q=8$ \\
\hline & & 1973Q4-2018Q3 & 1974Q2-2018Q3 & 1974Q4-2018Q3 & 1975Q2-2018Q3 \\
\hline Constant & & $-2.90^{\star \star \star}$ & $-4.35^{\star \star \star}$ & $-3.09^{* \star *}$ & $-4.03^{* * *}$ \\
\hline Yield curve slope $^{3}$ & 1.26 & $-0.37^{* * *}$ & $-0.94^{* * *}$ & $-0.74^{\star \star}$ & \\
\hline Unemployment gap ${ }^{4}$ & 0.62 & $1.47^{* *}$ & $2.93^{* \star *}$ & $1.54^{* * *}$ & \\
\hline \multicolumn{6}{|l|}{ Bank credit-to-GDP ratio } \\
\hline 3-year annual average change & 1.55 & & & & $0.64^{* * *}$ \\
\hline \multicolumn{6}{|l|}{ Real share prices } \\
\hline 1-year annual growth & 22.20 & $-0.04^{\star *}$ & & & \\
\hline \multicolumn{6}{|l|}{ Euro area real house prices } \\
\hline Difference, 1-yr less 3-yr annual avg growth & 2.05 & $-0.49^{* * *}$ & & & \\
\hline 3-year annual average growth & 2.95 & & $0.33^{*}$ & $0.21^{*}$ & $0.45^{\star \star *}$ \\
\hline \multicolumn{6}{|l|}{ Euro area real share prices } \\
\hline 3-year annual average growth & 12.67 & & & $0.07^{* *}$ & \\
\hline McFadden R-sqd & & 0.60 & 0.64 & 0.54 & 0.49 \\
\hline$\%$ of correct predictions ${ }^{5}$ & & $93 \%$ & $92 \%$ & $90 \%$ & $91 \%$ \\
\hline Downturns & & $92 \%$ & $92 \%$ & $92 \%$ & $82 \%$ \\
\hline Non-downturns & & $93 \%$ & $92 \%$ & $90 \%$ & $92 \%$ \\
\hline
\end{tabular}

(vi) Italy

\begin{tabular}{|c|c|c|c|c|c|}
\hline \multirow{3}{*}{$\begin{array}{l}\text { Binary dependent variable }{ }^{1} \text { : } \\
1=\text { severe downturn, } 0=\text { otherwise }\end{array}$} & \multirow{3}{*}{$\begin{array}{l}\text { Standard } \\
\text { deviation }^{2}\end{array}$} & \multicolumn{4}{|c|}{ Probit regression at horizon of $Q$ quarters } \\
\hline & & $Q=2$ & $Q=4$ & $Q=6$ & $Q=8$ \\
\hline & & \multicolumn{4}{|c|}{ 1971Q2-2018Q3 1971Q4-2018Q3 1971Q4-2018Q3 1976Q2-2018Q3 } \\
\hline Constant & & $-5.35^{\star \star *}$ & $-5.84^{* \star *}$ & $-6.88^{\star \star *}$ & $-7.72^{\star \star \star}$ \\
\hline Yield curve slope ${ }^{3,6}$ & 1.32 & $-0.27^{\star \star *}$ & $-0.49^{* * *}$ & & \\
\hline Long-term interest rate differential with Germany ${ }^{6}$ & 0.93 & $0.75^{\star \star *}$ & $0.39^{* *}$ & & \\
\hline \multicolumn{6}{|l|}{ Bank credit-to-GDP ratio } \\
\hline 3-year annual average change & 2.40 & & $0.34^{* * *}$ & $0.33^{\star \star \star}$ & $0.28^{\star \star *}$ \\
\hline \multicolumn{6}{|l|}{ Real share prices } \\
\hline 1-year annual growth & 31.61 & $-0.02^{* * *}$ & & & \\
\hline \multicolumn{6}{|l|}{ House price-to-income ratio } \\
\hline $\begin{array}{l}\text { 1-year average } \\
\text { 3-year average }\end{array}$ & 14.11 & $0.03^{\star *}$ & $0.04^{\star *}$ & $0.05^{\star \star \star}$ & $0.06^{\star * *}$ \\
\hline \multicolumn{6}{|l|}{ OECD bank credit-to-GDP ratio } \\
\hline 3-year annual average change & 1.02 & & & & $0.31^{* *}$ \\
\hline McFadden R-sqd & & 0.43 & 0.49 & 0.35 & 0.45 \\
\hline$\%$ of correct predictions ${ }^{5}$ & & $83 \%$ & $87 \%$ & $78 \%$ & $87 \%$ \\
\hline Downturns & & $87 \%$ & $87 \%$ & $80 \%$ & $96 \%$ \\
\hline Non-downturns & & $83 \%$ & $87 \%$ & $77 \%$ & $85 \%$ \\
\hline
\end{tabular}


(vii) Canada

\begin{tabular}{|c|c|c|c|c|c|}
\hline \multirow{3}{*}{$\begin{array}{l}\text { Binary dependent variable }{ }^{1} \text { : } \\
1=\text { severe downturn, } 0=\text { otherwise }\end{array}$} & \multirow{3}{*}{$\begin{array}{l}\text { Standard } \\
\text { deviation }\end{array}$} & \multicolumn{4}{|c|}{ Probit regression at horizon of $\mathrm{Q}$ quarters } \\
\hline & & $\mathrm{Q}=2$ & $Q=4$ & $\mathrm{Q}=6$ & $\mathrm{Q}=8$ \\
\hline & & 1974Q1-2018Q3 & 1974Q3-2018Q3 & 1976Q4-2018Q3 & 1975Q2-2018Q3 \\
\hline Constant & & $-2.95^{\star \star *}$ & $-2.45^{\star \star \star}$ & $-3.89^{* \star \star}$ & $-6.49^{* \star *}$ \\
\hline Yield curve slope ${ }^{3}$ & 1.51 & $-1.02^{* * *}$ & $-1.03^{* * *}$ & & \\
\hline Unemployment gap ${ }^{4}$ & 0.96 & & & $2.70^{\star \star \star}$ & $2.25^{\star \star \star}$ \\
\hline \multicolumn{6}{|l|}{ Unemployment rate } \\
\hline 1-year annual change & 1.04 & $0.61^{* * *}$ & & & \\
\hline \multicolumn{6}{|l|}{ Credit-to-GDP ratio } \\
\hline 3-year annual average change & 2.79 & & & $0.34^{\star \star}$ & $0.44^{\star \star \star}$ \\
\hline \multicolumn{6}{|l|}{ Real share prices } \\
\hline 1-year annual growth & 17.14 & $-0.04^{* \star *}$ & & & \\
\hline \multicolumn{6}{|l|}{ House price-to-income ratio } \\
\hline 1-year annual growth & 5.76 & & $-0.11^{* *}$ & & \\
\hline 3-year annual average growth & 3.68 & & $0.18^{\star *}$ & & \\
\hline 5-year annual average growth & 2.83 & & & $0.21^{* \star}$ & \\
\hline \multicolumn{6}{|l|}{ OECD credit-to-GDP } \\
\hline 3-year annual average change & 1.59 & $0.68^{\star \star \star}$ & $0.57^{\star \star \star}$ & & \\
\hline \multicolumn{6}{|l|}{ USA real house prices } \\
\hline 3-year annual average growth & 3.40 & & & & $0.57^{* *}$ \\
\hline \multicolumn{6}{|l|}{ OECD real share prices } \\
\hline 3-year annual average growth & 9.78 & & & & $0.09^{\star \star \star}$ \\
\hline McFadden R-sqd & & 0.69 & 0.65 & 0.72 & 0.65 \\
\hline$\%$ of correct predictions ${ }^{5}$ & & $91 \%$ & $88 \%$ & $93 \%$ & $90 \%$ \\
\hline Downturns & & $92 \%$ & $88 \%$ & $95 \%$ & $100 \%$ \\
\hline Non-downturns & & $91 \%$ & $88 \%$ & $93 \%$ & $89 \%$ \\
\hline
\end{tabular}

Notes to Tables A1 (i)- (vii):

1) The dependent variable is a binary variable taking the value of 1 in a severe downturn, defined as being during a run of quarters when GDP per capita falls cumulatively by at least $2 \%$ points, and zero otherwise. The definition of downturn periods is different for Japan (see main text). See Table 1 in main text for dating of downturn periods.

2) The standard deviation of the explanatory variable over the full sample.

3) The slope of the yield curve is measured as the difference between the interest rate on 10-year government bonds and a short-term interest rate, which is usually taken as the rate on a 3-month Treasury bill. For the United States, a measure of the term premium, computed by the New York Fed, is also subtracted from the yield curve slope (see Adrian et al, 2013).

4) The unemployment gap is the OECD measure of the equilibrium unemployment less the unemployment rate, so that a positive value indicates that the labour market is over-heating.

5) Predictions categorised according to a $15 \%$ probability threshold.

6) For Italy, the yield curve slope is used in the period prior to the creation of the euro, and after the creation of the euro the long-term interest differential with Germany is used.

For the probit regression at a horizon of $\mathrm{Q}$ quarters $(\mathrm{Q}=2,4,6$ or 8$)$ all explanatory variables enter the equations lagged by $Q$ quarters except house price variables which are lagged an extra quarter and credit variables which are lagged 2 extra quarters (because of the additional time delays in data availability). Statistical significance of coefficients at the $1 \%, 5 \%$ and $10 \%$ levels are denoted by '***', '**' and '*”, respectively.

Source: Data from OECD Analytical Database and Bank for International Settlements. 
Figure A.1 Probit model downturn predictions ${ }^{1}$

United States
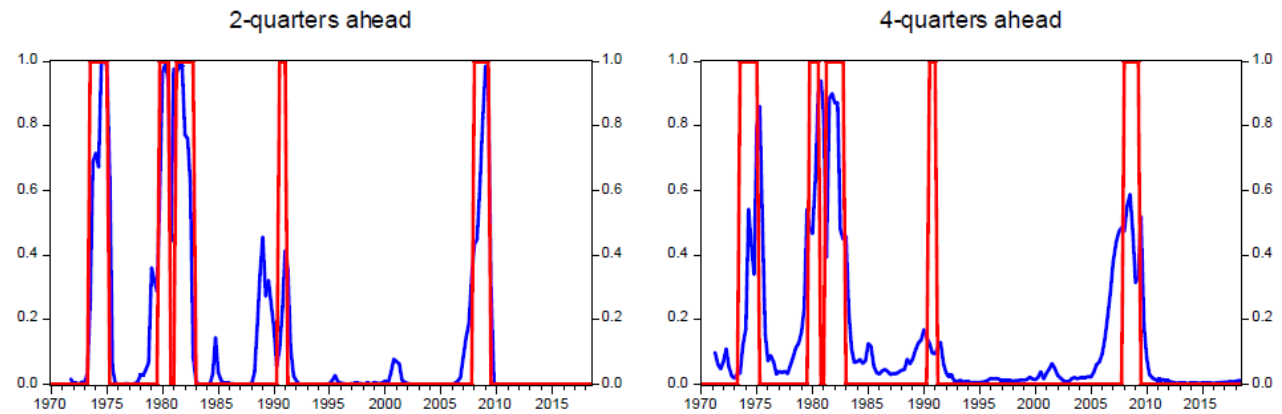

6-quarters ahead

8-quarters ahead
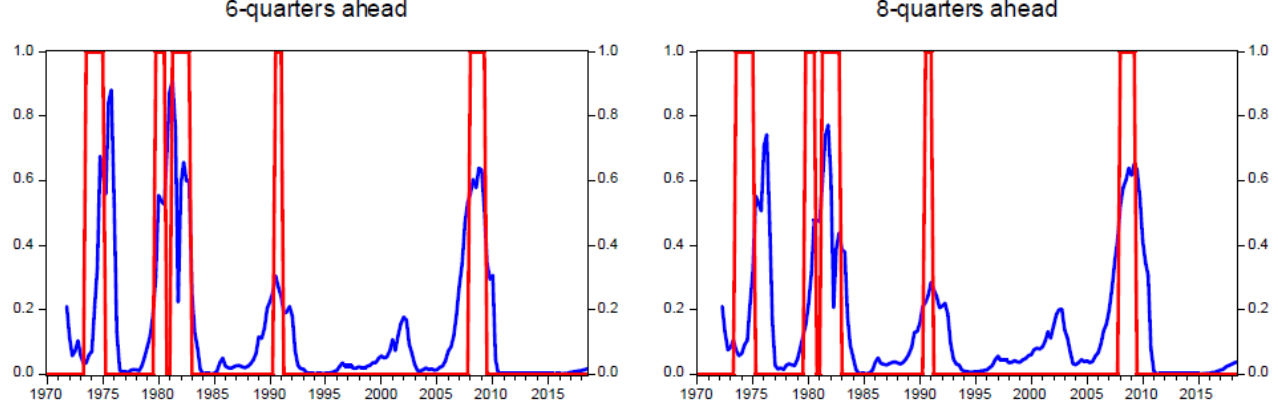

-Forecast - Actual

Japan
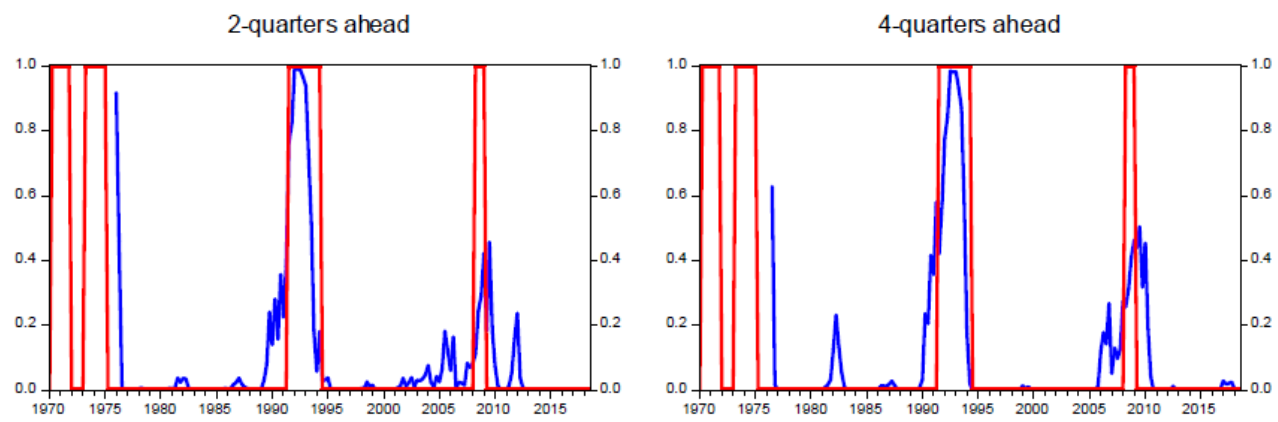

-quarters ahead

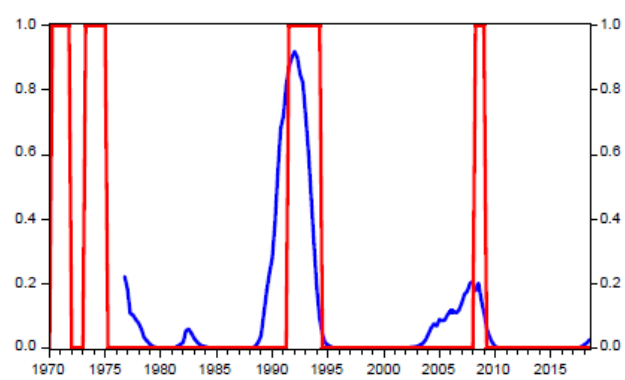

8-quarters ahead

-Forecast —Actual 


\section{Germany}
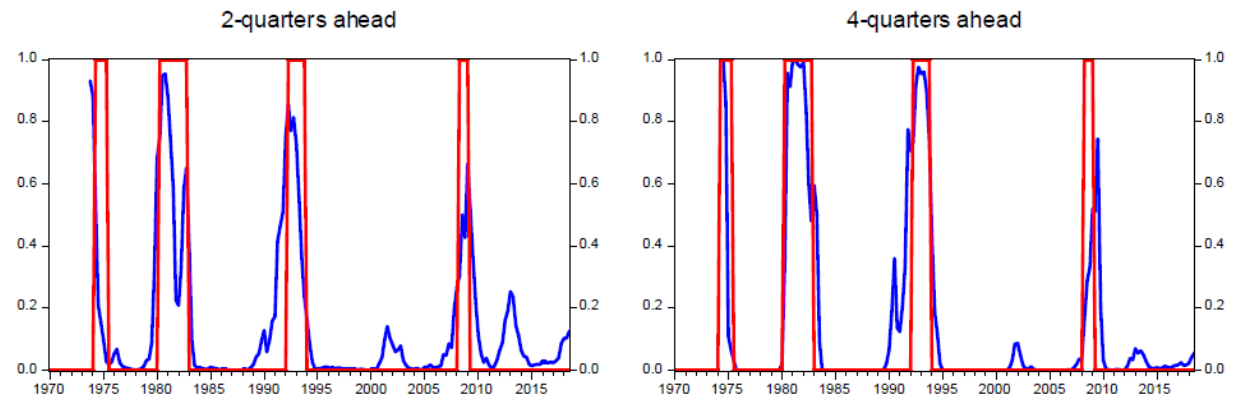

6-quarters ahead

8-quarters ahead
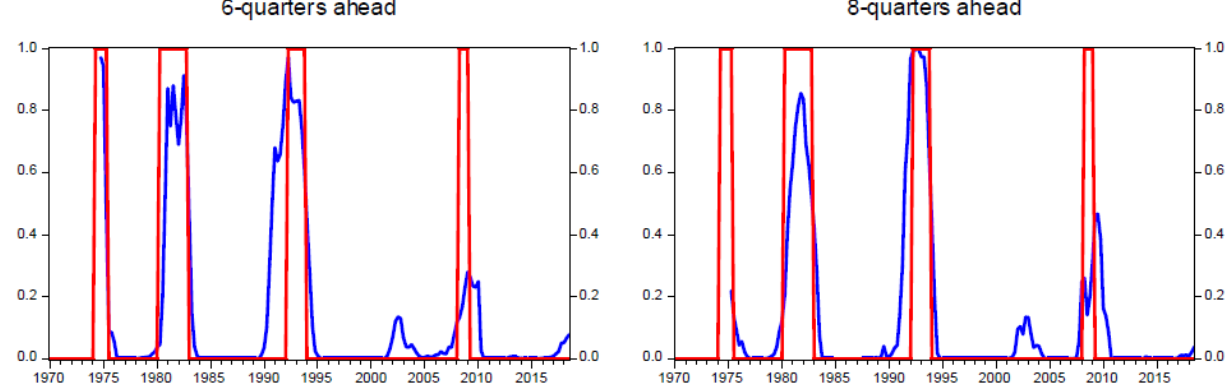

-Forecast - Actual

United Kingdom
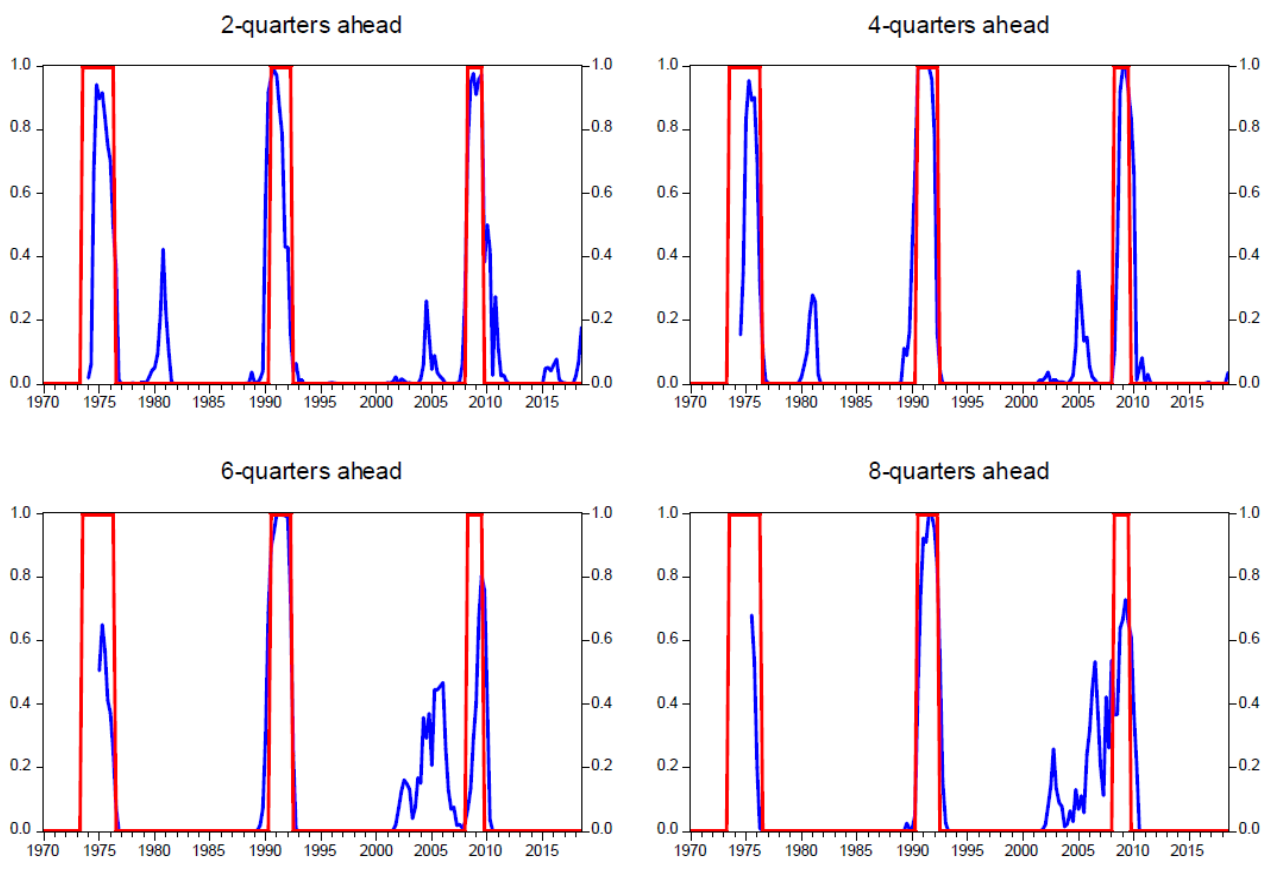

-Forecast - Actual 
France
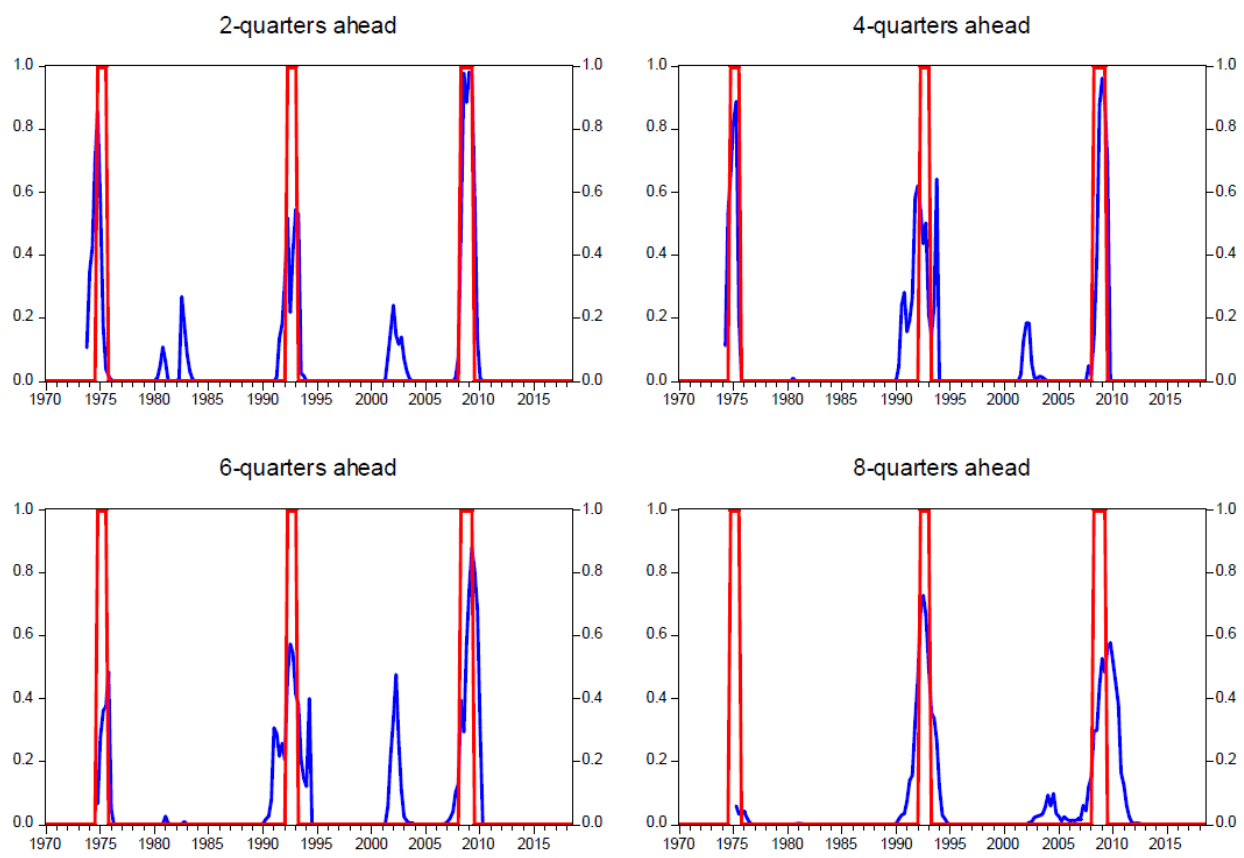

Italy
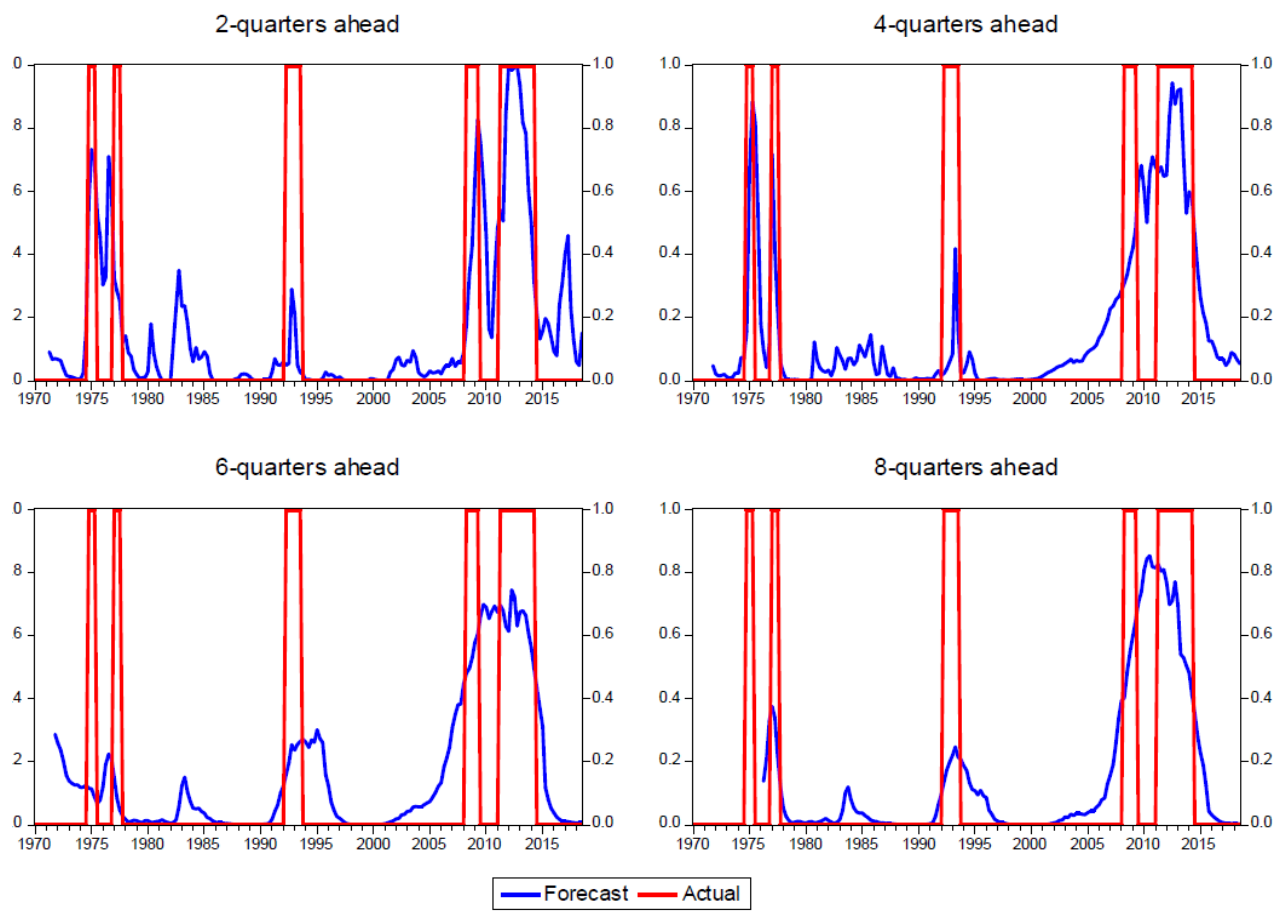


\section{Canada}
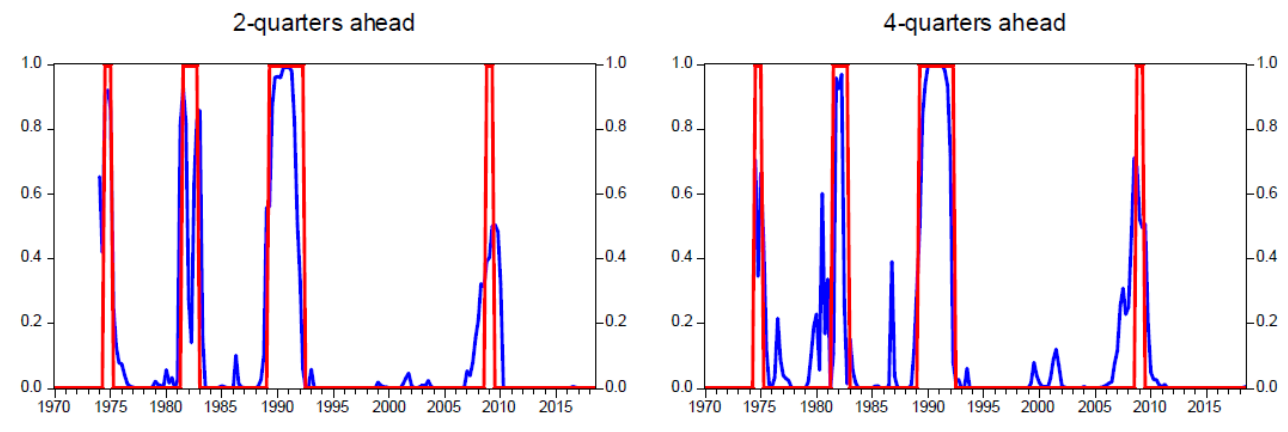

6-quarters ahead

8-quarters ahead
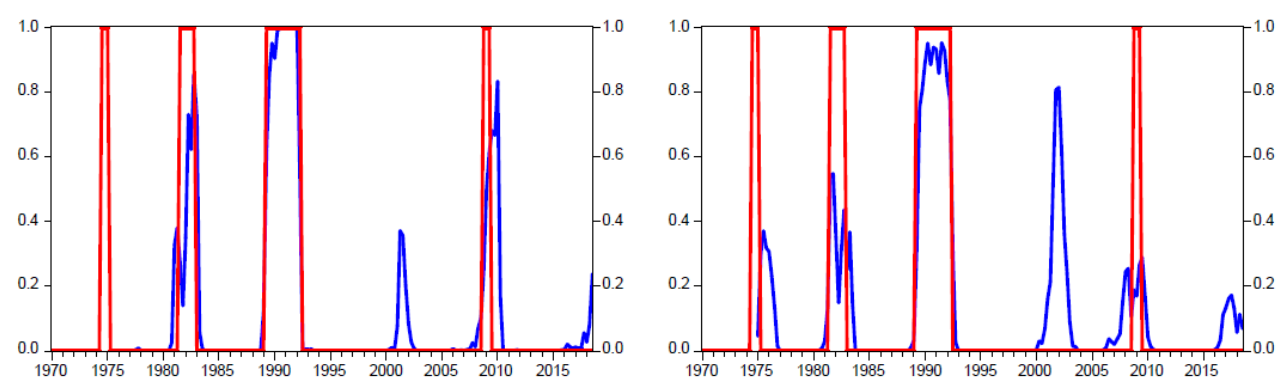

Note:

1. The scale on the vertical axis ranges from zero to one: for the 'forecast' this is the predicted probability of a downturn; the 'actual' takes a value of one when there is a severe downturn and zero otherwise. 
Annex B. The two-piece normal distribution and prediction intervals

\section{The two-piece normal distribution}

The two-piece, or split, normal distribution has come to prominence in macroeconomics because of its use by central banks, especially the Bank of England (Britton et al., 1997; Bank of England, 2005) and Riksbank (Blix and Sellin, 1998), in constructing asymmetric fan charts, but it has a much longer history in statistical theory (Wallis, 2014).

The two-piece normal distribution can be thought of as the combination of two halves of two different normal distributions with the same mode, $\mu$, but different standard deviations, $\sigma_{1}$ and $\sigma_{2}$, with the respective probability density functions being re-scaled to have the same value at the mode. If $\sigma_{1}>\sigma_{2}$ then the distribution is skewed to the left so that the mean is less than the mode, whereas if $\sigma_{1}<\sigma_{2}$ then the distribution is skewed to the right with the mean exceeding the mode. The resulting two-piece normal distribution can be summarised in terms of the three parameters $\left(\mu, \sigma_{1}, \sigma_{2}\right)$.

In this paper whenever the two-piece normal is used, namely when the probit probabilities suggest there is a significant downturn risk, the distribution is skewed to the left, so that $\sigma_{1}>\sigma_{2}$ and the mean is less than the mode. In the example illustrated in Figure B1 - which is computed in Turner (2017) to be typical of the distribution in the year-ahead forecast of GDP growth for a G7 country when there is a high risk of a severe downturn - the twopiece normal distribution is constructed by combining normal distributions with common mode equal to 2 (representing the baseline year-ahead forecast of GDP growth) and standard deviations of $\sigma_{1}=3.0$ and $\sigma_{2}=1.3$.

\section{Figure B.1. The probability density function of an illustrative two-piece normal distribution}

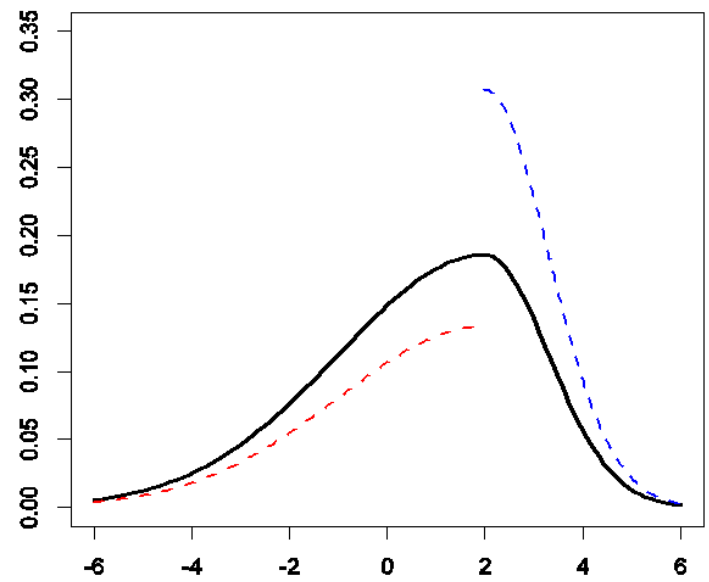

Note: The two-piece normal probability density function (pdf) represented by the solid black line is formed by re-scaling and combining two normal pdfs here represented by the dashed curves; the left-hand-side dashed curve is a normal pdf with mode of 2 and standard deviation of 3.0, the right-hand-side dashed curve has the same mode with a standard deviation of 1.3 . The parameterisation roughly reflects the pdf of a year-ahead forecast of GDP growth for a typical G7 country when there is risk of a downturn based on Turner (2017). 


\section{The type of prediction intervals}

Once the parameters of the two-piece normal distribution are determined, given that the distribution is asymmetric, there is still an issue as to how to determine prediction intervals; i.e. how to determine the values $(\mathrm{a}, \mathrm{b})$ defining a prediction interval of $\mathrm{p} \%$, where $0 \%<\mathrm{p} \%<100 \%$, so that the outcome in question (here year-ahead GDP growth) will occur within the interval $(\mathrm{a}, \mathrm{b})$ with probability $\mathrm{p} \%$.

An intuitive choice would seem to be central prediction intervals so that the prediction interval covers the stated proportion in the centre of the distribution, with the remaining probability split equally between the upper- and lower-tails outside this interval. This is, however, not the usual practice of central banks such as the Bank of England, which instead adopt highest probability density (HPD) intervals that coincide with choosing the shortest interval (b-a) for any given $\mathrm{p} \%$ (Casella and Berger, 2002). The present paper also follows the Bank of England practice of using HPD intervals.

While these two approaches give the same intervals for symmetric distributions, they are different when the distribution is asymmetric. Wallis $(1999,2004)$ argues for replacing the Bank of England intervals with central intervals on the grounds that many readers of the Inflation Report may wrongly interpret the $90 \%$ interval as implying a $5 \%$ probability that the outcome (inflation or GDP growth) will exceed the upper limit of the fan chart. $\mathrm{He}$ further argues that it is difficult to justify the Bank's choice of intervals from a loss-function perspective.

An important difference between the two approaches is that as the prediction interval $\mathrm{p} \%$ is progressively reduced, in the case of central prediction intervals the distribution collapses to the median, whereas in the case of HPD intervals it collapses to the mode. This difference can be visually striking as the baseline forecast (the mode) may no longer appear in the darkest shaded intervals of the fan chart if central prediction intervals are adopted instead of HPD intervals.

In terms of the previous example illustrated in Figure B1, a 90\% central prediction interval covers the interval $(-3.40,3.80)$ with upper- and lower-tail probabilities of exactly $5 \%$ (Figure B2), whereas the $90 \%$ HPD prediction interval covers the interval $(-2.94,4.14)$ with a lower-tail probability of $7.0 \%$ and an upper-tail probability of $3.0 \%$ (Figure B3). Moreover, whereas the mode is, by construction, always within the HPD $\mathrm{p} \%$ prediction interval for all values of $\mathrm{p} \%$, the mode lies outside the central prediction intervals as $\mathrm{p} \%$ is reduced below $40 \%$, as illustrated for a $30 \%$ central prediction interval in Figure B2. In terms of the associated forecast fan charts, this implies that the baseline forecast (the mode) will always be within the darkest (i.e. tightest) prediction interval shown when HPD prediction intervals are used, but this is not guaranteed if central prediction intervals are used. 
Figure B2. Central prediction intervals for the two-piece normal distribution

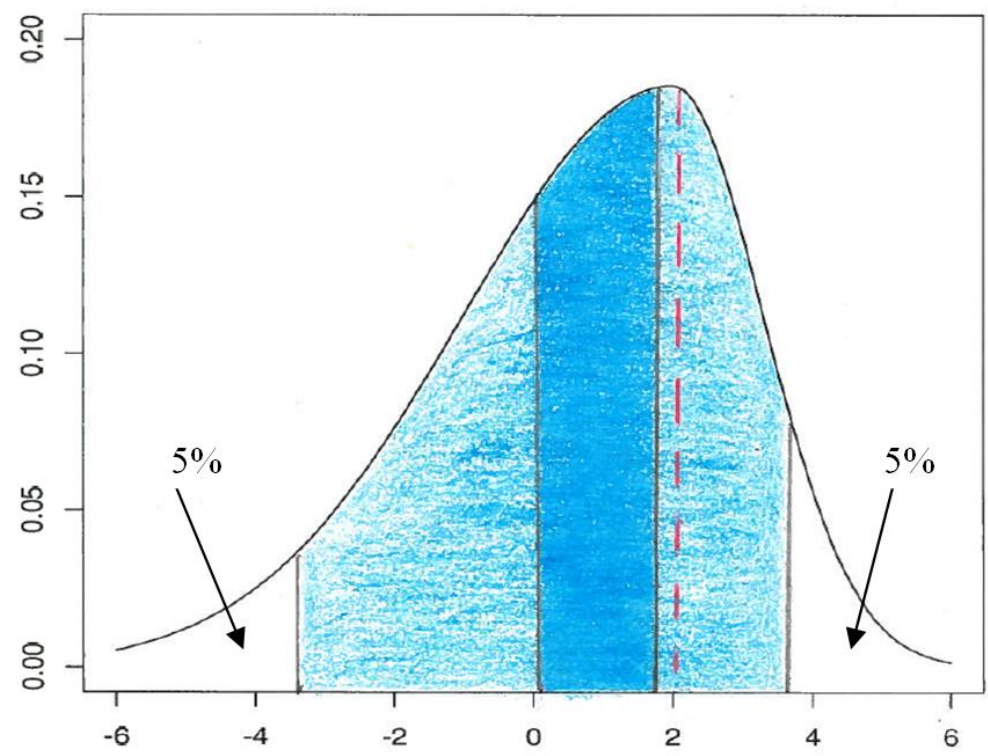

Note: The illustrative two-piece normal distribution has the same underlying parameters as that described in Figure B1. The lighter shaded area corresponds to a $90 \%$ central prediction interval, within which the darker shaded area corresponds to the $30 \%$ central prediction interval. The vertical red dashed line corresponds to the mode.

Figure B3. Highest probability density prediction intervals for the two-piece normal distribution

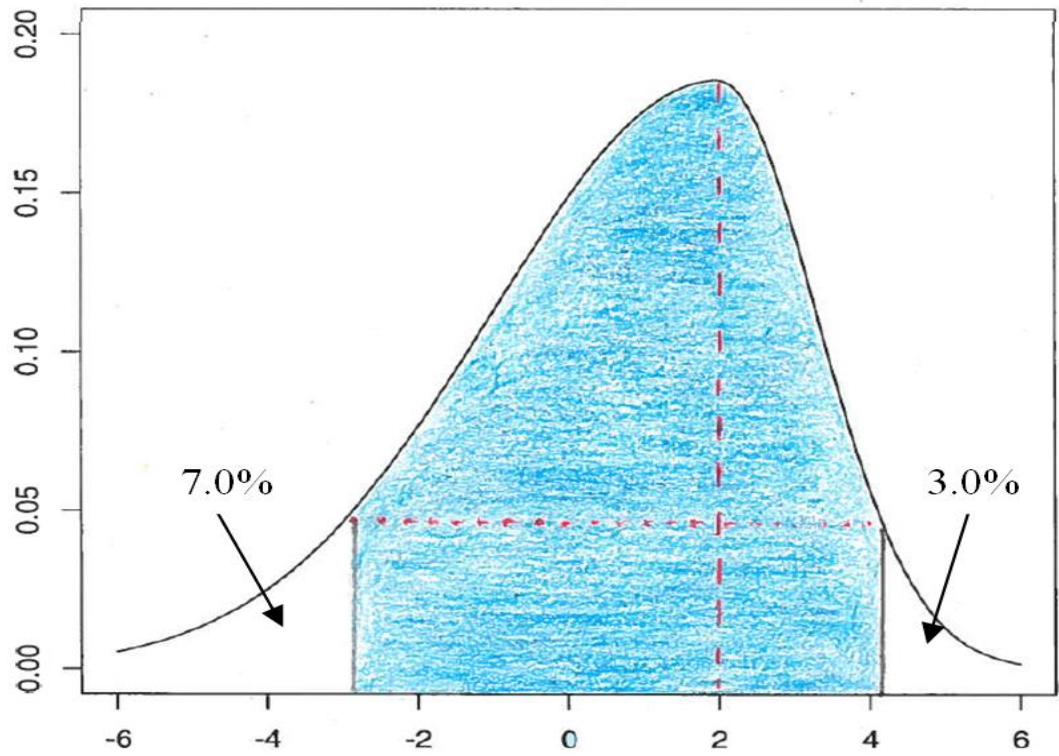

Note: The illustrative two-piece normal distribution has the same underlying parameters as that described in Figure B1. The shaded area corresponds to a $90 \%$ highest probability density prediction interval and the vertical red dashed line corresponds to the mode. 


\section{The number of prediction intervals}

A further issue relates to the number of prediction intervals shown in the fan chart. When the Bank of England began publishing fan charts they displayed intervals for each decile cumulatively $10 \%, 20 \%, 30 \%$, etc. up to $90 \%$, although they have also more recently begun publishing an additional version of the fan chart with (only) three wider bands, covering the cumulative intervals $30 \%, 60 \%$ and $90 \%$. Arguably, the latter version is visually easier to interpret. Moreover, when surveyed, macroeconomic forecasters often resort to very rounded numbers in attaching probabilities to possible outcomes and in the light of this "uncertain uncertainty" (Boero et al., 2015), showing fewer prediction intervals seems more appropriate. Accordingly, the fan charts in the current paper only distinguish three prediction intervals at $50 \%, 70 \%$ and $90 \%$. An analogy with the appropriate disaggregation of prediction intervals might be with the reporting of the number of decimal places; quoting a number with many decimal places suggests a degree of confidence or certainty in a number, which in macroeconomic forecasting is rarely the case. Moreover, it is less easy to quickly discern the main messages from a table of many numbers, if each number is displayed with a large number of spurious decimal places. 